\title{
不同形貌结构 $\mathrm{Li}_{4} \mathrm{Ti}_{5} \mathrm{O}_{12}$ 负极材料的最新进展
}

\author{
张永龙胡学步* 徐云兰明亮 \\ (重庆理工大学化学化工学院 重庆 400054)
}

\begin{abstract}
摘要 由于电子和信息行业的需要, 过去十年锂离子电池得以快速发展. 目前, 锂离子电池仍呈现需求量增长的趋势, 对锂离子电池的安全性要求也越来越高. 因此促使寻找一种比碳/石墨材料更安全, 循环性能更理想的锂离子电池负 极材料以满足电动汽车等新兴行业的需求. 尖晶石型 $\mathrm{Li}_{4} \mathrm{Ti}_{5} \mathrm{O}_{12}$ 作为 “零应变材料” 具有优异的循环稳定性、价格便宜、 容易制备、较高的平台电压和良好的安全性, 已成为锂离子动力电池负极材料的研究热点, 被认为是目前最具应用前 景的锂离子电池负极材料. 由于形貌选择对于 $\mathrm{Li}_{4} \mathrm{Ti}_{5} \mathrm{O}_{12}$ 材料的电化学性能有着至关重要的影响, 本文综述了球形、多 孔(中空)结构、纳微结构、核壳结构等不同形貌 $\mathrm{Li}_{4} \mathrm{Ti}_{5} \mathrm{O}_{12}$ 的合成及其性能研究的最新进展; 总结了各种形貌的优点, 已 解决和待解决的问题, 常用合成方法以及各自的适应领域; 并对 $\mathrm{Li}_{4} \mathrm{Ti}_{5} \mathrm{O}_{12}$ 材料的发展趋势进行了展望.
\end{abstract}

关键词 $\mathrm{Li}_{4} \mathrm{Ti}_{5} \mathrm{O}_{12}$; 形貌结构; 进展; 负极材料; 锂离子电池

\section{Recent Progress of $\mathrm{Li}_{4} \mathrm{Ti}_{5} \mathrm{O}_{12}$ with Different Morphologies as Anode Material

\author{
Zhang, Yonglong $\mathrm{Hu}$, Xuebu* Xu, Yunlan Ding, Mingliang \\ (College of Chemistry and Chemical Engineering, Chongqing University of Technology, Chongqing 400054)
}

\begin{abstract}
Lithium-ion battery has developed rapidly in the past decades due to growing needs of electronic and information industries. Nowadays, the demand for lithium-ion batteries is still increasing and safety requirements are higher and higher. Therefore, exploration of a new anode material that is high safety and excellent cycle ability, as compared to commercial carbon/graphite materials, has been extensively attempted to meet the new need such as electric vehicles industry. Spinel $\mathrm{Li}_{4} \mathrm{Ti}_{5} \mathrm{O}_{12}$ as an anode material of power lithium-ion battery has become a research hotspot due to its appealing features such as "zero-strain" structure characteristic, excellent cycle stability, low cost, simple synthesis, high safety feature and flat charge-discharge voltage plateau $\left(1.55 \mathrm{~V} \mathrm{vs.} \mathrm{Li} / \mathrm{Li}^{+}\right)$. It is also considered as one of the most promising anode material for lithium-ion battery. Despite many advantages associated with $\mathrm{Li}_{4} \mathrm{Ti}_{5} \mathrm{O}_{12}$, it can not meet the need of large-scale applications due to its pretty low electric conductivity $\left(10^{-13} \mathrm{~S} \cdot \mathrm{cm}^{-1}\right)$, moderate $\mathrm{Li}^{+}$diffusion coefficient $\left(10^{-9} \sim 10^{-13} \mathrm{~cm}^{2} \cdot \mathrm{s}^{-1}\right)$ and theoretical capacity $\left(175 \mathrm{mAh} \bullet \mathrm{g}^{-1}\right)$. Several methods have been utilized to improve the conductivity and energy density of $\mathrm{Li}_{4} \mathrm{Ti}_{5} \mathrm{O}_{12}$, such as synthesis of nano-sized particle, ion doping, doping $\mathrm{Li}_{4} \mathrm{Ti}_{5} \mathrm{O}_{12}$ with other metals or metal oxides, coating $\mathrm{Li}_{4} \mathrm{Ti}_{5} \mathrm{O}_{12}$ with conductive carbons, nitridation on $\mathrm{Li}_{4} \mathrm{Ti}_{5} \mathrm{O}_{12}$ surface and composite anode materials prepared by $\mathrm{Li}_{4} \mathrm{Ti}_{5} \mathrm{O}_{12}$ and other anodes. In addition, unique structure has been proved as an effective way to improve the electric conductivity of the material. Moreover, morphology has also an important effect on electrochemical performances of $\mathrm{Li}_{4} \mathrm{Ti}_{5} \mathrm{O}_{12}$ such as specific capacity, specific energy, specific power, high rate performance and cycle life. This review focuses on the present status of different morphologies $\mathrm{Li}_{4} \mathrm{Ti}_{5} \mathrm{O}_{12}$ including spherical structure, porous (hollow) structure, nano-micro structure, core-shell structure, one-dimensional, two-dimensional and three-dimensional nanostructures, then summarized their advantages, resolved and unresolved problems, common synthesis methods and application areas, respectively. At last, the future development prospects of $\mathrm{Li}_{4} \mathrm{Ti}_{5} \mathrm{O}_{12}$ are presented.
\end{abstract}

Keywords $\mathrm{Li}_{4} \mathrm{Ti}_{5} \mathrm{O}_{12}$; morphology; progress; anode material; lithium-ion battery

\section{1 引言}

作为未来的清洁能源之一, 锂离子电池具有平台电 压高、体积小、重量轻、无记忆效应、可靠性好等优点, 目前已应用于电动车及混合电动车的动力电源. 但是, 锂离子电池的安全与寿命问题一直制约着电动汽车的 普及和大规模应用 ${ }^{[1]}$. 因此, 寻找一种比石墨材料更安
全，循环性能更理想的锂离子电池负极材料以满足电动 汽车等新兴行业的需求成为当务之急.

尖晶石型 $\mathrm{Li}_{4} \mathrm{Ti}_{5} \mathrm{O}_{12}$ 被认为是可能取代目前商品化 石墨负极的材料之一 ${ }^{[2]}$. 该材料具有 “零应变” 结构、 平坦的充放电平台 $\left(1.55 \mathrm{~V}\right.$ vs. $\left.\mathrm{Li}^{\prime} / \mathrm{Li}^{+}\right)$、循环性能好、安 全、容易制备等优点 ${ }^{[3]}$; 因此作为动力锂离子电池的负 极材料有着很大的研究价值和商业应用前景.

\footnotetext{
*E-mail: xuebu@cqut.edu.cn

Received April 18, 2013; published June 27, 2013.

Project supported by the National Natural Science Foundation of China (Nos. 21206203, 21077140).

项目受国家自然科学基金(Nos. 21206203, 21077140)资助.
} 
然而 $\mathrm{Li}_{4} \mathrm{Ti}_{5} \mathrm{O}_{12}$ 材料有两点不足: 一是电子和离子电 导率较低(分别为 $10^{-13} \mathrm{~S} \cdot \mathrm{cm}^{-1}$ 和 $10^{-9} \sim 10^{-13} \mathrm{~cm}^{2} \cdot \mathrm{s}{ }^{-1}$ ) 电子在 $\mathrm{Li}_{4} \mathrm{Ti}_{5} \mathrm{O}_{12}$ 中发生跃迁的能隙大于 $2 \mathrm{eV}$, 为绝缘体 材料 ${ }^{[5]}$, 导致其大电流放电条件下容量衰减快, 倍率性 能差, 严重限制了其大规模应用 ${ }^{[6]}$; 二是其理论比容量 仅为 $175 \mathrm{mAh} \cdot \mathrm{g}^{-1}{ }^{[7]}$, 相比于理论容量为 $372 \mathrm{mAh} \cdot \mathrm{g}^{-1}$ 的商业化石墨负极 ${ }^{[8]}$, 能量密度较低.

针对 $\mathrm{Li}_{4} \mathrm{Ti}_{5} \mathrm{O}_{12}$ 上述两个缺点, 研究者们开展了大量 的研究工作, 目前的改良方法主要包括制备纳米级颗 粒 ${ }^{\text {[9 11] 、离子掺杂 }}{ }^{[12 \sim 14]}$ 、金属掺杂 ${ }^{[15,16]}$ 、碳掺杂及包 覆 ${ }^{[17 ~ 19]}$, 或与其它电极材料组成复合电极材料等 ${ }^{[20 ~ 22]}$. 除此之外, 形貌的选择对于 $\mathrm{Li}_{4} \mathrm{Ti}_{5} \mathrm{O}_{12}$ 材料的电化学性能 也有至关重要的影响. 鉴于此, 本文讨论了不同形貌 $\mathrm{Li}_{4} \mathrm{Ti}_{5} \mathrm{O}_{12}$ 的制备及其形貌对其电化学性能的影响, 并对 $\mathrm{Li}_{4} \mathrm{Ti}_{5} \mathrm{O}_{12}$ 材料的未来发展方向进行了展望.

\section{2 球形颗粒}

为提高 $\mathrm{Li}_{4} \mathrm{Ti}_{5} \mathrm{O}_{12}$ 的能量密度, 许多研究者制备了球 形 $\mathrm{Li}_{4} \mathrm{Ti}_{5} \mathrm{O}_{12}$ 材料. 首先, 球形颗粒有利于颗粒间的接触, 可实现产物的紧密堆积, 具有较高的振实密度和大的体 积容量 ${ }^{[23]}$. 其次, 球形颗粒具有优异的流动性、分散性 和可加工性能 ${ }^{[24]}$, 因此被广泛应用于 $\mathrm{Li}_{4} \mathrm{Ti}_{5} \mathrm{O}_{12}$ 材料的 制备 ${ }^{[25 ~ 34] . ~}$

喷雾干燥法具有处理温度低、反应速率快、所得产 品分散性好、颗粒均匀等优点, 是制备球形 $\mathrm{Li}_{4} \mathrm{Ti}_{5} \mathrm{O}_{12}$ 的 常用方法. He 等 ${ }^{[25]}$ 通过喷雾干燥法并随后高温炦烧, 获 得了球形纳米晶 $\mathrm{Li}_{4} \mathrm{Ti}_{5} \mathrm{O}_{12}$. 经 $\mathrm{SEM}$ 观察, 产物为 100 $\mathrm{nm}$ 大小的多孔球形结构, 其在 $1 \mathrm{C}$ 和 $2 \mathrm{C}$ 下的首次放电 量分别为 $163 \mathrm{mAh} \cdot \mathrm{g}^{-1}$ 和 $153 \mathrm{mAh} \cdot \mathrm{g}^{-1}$, 循环 100 次后容 量保持率分别为 $97 \%$ 和 $95 \%$.

同样采用喷雾干燥的方法, $\mathrm{Wu}$ 等 ${ }^{[26]}$ 得到的均匀纳 米球形 $\mathrm{Li}_{4} \mathrm{Ti}_{5} \mathrm{O}_{12}$ 在 $0.1 \mathrm{C}$ 低倍率下的首次放电量为 174.8 $\mathrm{mAh} \cdot \mathrm{g}^{-1}$. 即使在 $20 \mathrm{C}$ 的大倍率下, 其首次放电量依然 有 $111.9 \mathrm{mAh} \cdot \mathrm{g}^{-1}$, 且循环 100 次后的容量保持率为 $89.0 \%$, 显示了较高的比容量, 良好的循环稳定性和优 秀的倍率性能.

该法不仅可合成球形纯相 $\mathrm{Li}_{4} \mathrm{Ti}_{5} \mathrm{O}_{12}$, 还可应用于球 形复合 $\mathrm{Li}_{4} \mathrm{Ti}_{5} \mathrm{O}_{12}$ 材料的制备. Kadoma 等 ${ }^{[27]}$ 以不同碳源 应用喷雾干燥法和固相法煅烧合成了过锂球形 $\mathrm{Li}_{4.3} \mathrm{Ti}_{5} \mathrm{O}_{12} / \mathrm{C}$ 复合物. 其中以聚乙烯为碳源的球形 $\mathrm{Li}_{4.3} \mathrm{Ti}_{5} \mathrm{O}_{12} / \mathrm{C}$ 复合物表现出了最好的倍率性能. TEM 下 观察发现, $\mathrm{Li}_{4.3} \mathrm{Ti}_{5} \mathrm{O}_{12}$ 表面包覆有一层均匀的无定形碳, 呈现 $1 \mu \mathrm{m}$ 左右的规则球形, $10 \mathrm{C}$ 时的最大放电容量有 $117 \mathrm{mAh} \cdot \mathrm{g}^{-1}$.

固相法因其操作简单，适合于大规模应用，亦是合 成球形颗粒的常规方法. Zhao 等 ${ }^{[28]}$ 通过高温固相法反应 并经后来的 $\mathrm{NH}_{3}$ 气氛中的氮化过程, 获得了球形氮化介 孔 $\mathrm{Li}_{4} \mathrm{Ti}_{5} \mathrm{O}_{12}$ 颗粒. 在 $10 \mathrm{C}$ 和 $20 \mathrm{C}$ 下的首次放电量分别
为 $138 \mathrm{mAh} \cdot \mathrm{g}^{-1}$ 和 $120 \mathrm{mAh} \cdot \mathrm{g}^{-1}$, 其中 $10 \mathrm{C}$ 下循环 100 次后的容量保持率为 $94 \%$, 其倍率性和循环稳定性得到 了明显提升.

除此之外，作为典型湿法合成方法的水热法，也是 制备电极材料常见的方法之一. Jung 等 ${ }^{[29]}$ 利用水热法合 成了包覆碳的 $\mathrm{Li}_{4} \mathrm{Ti}_{5} \mathrm{O}_{12}$ 微球颗粒, 其平均粒径在 500 $\mathrm{nm}$ 左右, 振实密度高达 $1.31 \mathrm{~g} \bullet \mathrm{cm}^{-3}$, 超过纯 $\mathrm{Li}_{4} \mathrm{Ti}_{5} \mathrm{O}_{12}$ 振实密度的 1.5 倍, 将其与具有高比表面积的活性碳组 成无水超级电容器, 其最大能量密度和功率密度分别达 到了 $57 \mathrm{Wh} \cdot \mathrm{L}^{-1}$ 和 $2600 \mathrm{~W} \cdot \mathrm{L}^{-1}$, 循环 1000 次后的容量 保持率依然有 $95 \%$, 研究显示了高能量密度特性和快速 充放电性能, 非常适合作为超级电容器的负极材料.

无独有偶, Yan 等 ${ }^{[30]}$ 同样通过水热法合成 Li-Ti-O 前 驱体后, 在 $800{ }^{\circ} \mathrm{C}$ 下炼烧获得球形的 $\mathrm{Li}_{4} \mathrm{Ti}_{5} \mathrm{O}_{12}$ 颗粒. 所 得产物呈规则球形形貌, 粒径约为 $0.5 \mu \mathrm{m}$ (如图 1), 振 实密度达到 $1.10 \mathrm{~g} \cdot \mathrm{cm}^{-3}$. 在 $0.2 \mathrm{C}$ 下的首次放电量为 $165 \mathrm{mAh} \cdot \mathrm{g}^{-1}$, 循环 70 次后容量保持率为 $97 \%, 2 \mathrm{C}$ 下循 环 100 次后仍有 $123 \mathrm{mAh} \cdot \mathrm{g}^{-1}$ 的放电比容量.

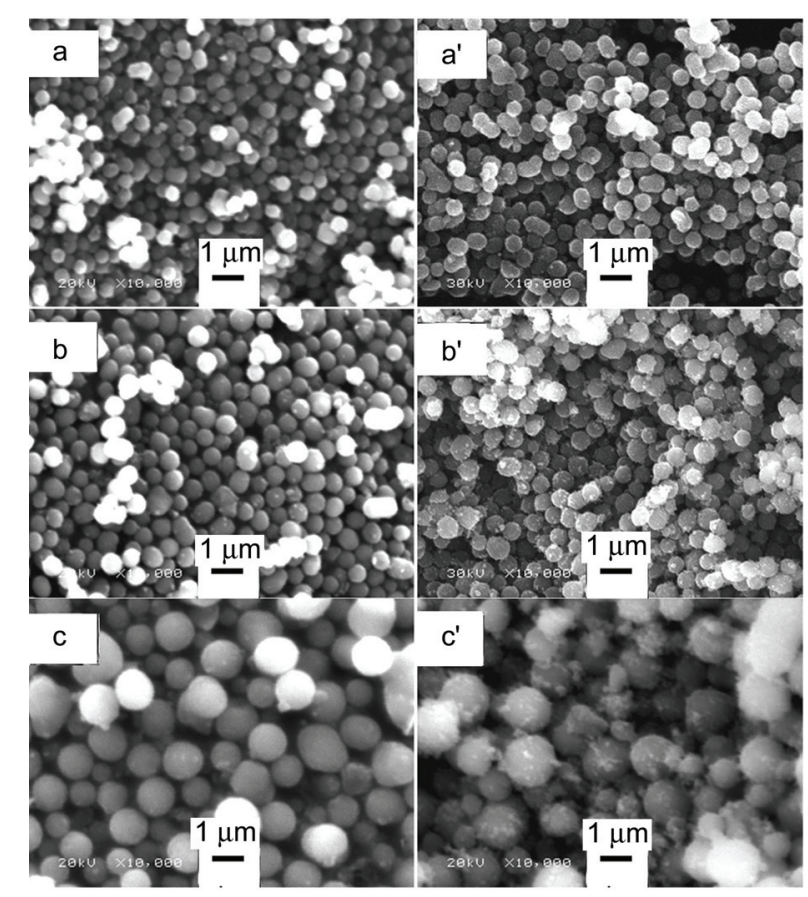

图 1 水热法获得的不同大小的前驱体 $\left(\mathrm{a}^{\prime} \sim \mathrm{c}^{\prime}\right)$ 和终产物球形 $\mathrm{Li}_{4} \mathrm{Ti}_{5} \mathrm{O}_{12}$ 的 SEM 图(a) $0.3 \mu \mathrm{m}$; (b) $0.5 \mu \mathrm{m}$; (c) $1.0 \mu \mathrm{m}^{[30]}$

Figure 1 SEM micrographs of precursors $\left(a^{\prime} \sim c^{\prime}\right)$ obtained after the hydrothermal reaction and the final spherical $\mathrm{Li}_{4} \mathrm{Ti}_{5} \mathrm{O}_{12}$ samples with different particle size (a) $0.3 \mu \mathrm{m}$, (b) $0.5 \mu \mathrm{m}$ and (c) $1.0 \mu \mathrm{m}$, respectively $^{[30]}$

为了研究大颗粒 $\mathrm{Li}_{4} \mathrm{Ti}_{5} \mathrm{O}_{12}$ 微球的电化学性能, Zhang 等 ${ }^{[31]}$ 通过水热法合成了大小为 $1 \sim 5 \mu \mathrm{m}$ 的 $\mathrm{Li}_{4} \mathrm{Ti}_{5} \mathrm{O}_{12}$ 微球, 其在 $0.1 \mathrm{C}$ 和 $1 \mathrm{C}$ 下的首次放电量分别为 $172.5 \mathrm{mAh} \cdot \mathrm{g}^{-1}$ 和 $152.7 \mathrm{mAh} \cdot \mathrm{g}^{-1}$, 且循环 50 次后的容量 保持率分别为 $92.8 \%$ 和 $96.7 \%$. 但在 $10 \mathrm{C}$ 倍率下的比容 量仅为 $82.2 \mathrm{mAh} \cdot \mathrm{g}^{-1}$, 相对较低, 表明大颗粒微球的倍 
率性能较小颗粒微球差, 这归结于大的颗粒尺寸导致锂 离子和电子的迁移距离较大.

相比之下, $\mathrm{Li}^{\text {等 }}{ }^{[32]}$ 基于乙二醇钛在 $\mathrm{LiOH}$ 水溶液中 的原位转换机制, 以吸附有 $\mathrm{AuCl}_{4}^{-}$的乙二醇钛为原料, 采用水热法与 $\mathrm{LiOH}$ 混合反应制得了球形前驱体, 通过 煅烧合成了多孔球形的 $\mathrm{Au} / \mathrm{Li}_{4} \mathrm{Ti}_{5} \mathrm{O}_{12}$ 复合材料(如图 2), 该法具有简单、环保的特点. 所得产物呈规律一致且表 面光滑的球形，粒径约为 $400 \sim 500 \mathrm{~nm}$ ，比表面积达 166 $\mathrm{m}^{2} \cdot \mathrm{g}^{-1}$. 经电化学测试, $5 \mathrm{C}$ 和 $10 \mathrm{C}$ 下的首次放电容量分 别为 $135 \mathrm{mAh} \cdot \mathrm{g}^{-1}$ 和 $127 \mathrm{mAh} \cdot \mathrm{g}^{-1}, 20 \mathrm{C}$ 下的放电容量也 有 $120 \mathrm{mAh} \cdot \mathrm{g}^{-1}$. 同时, $1 \mathrm{C}$ 倍率下循环 100 次后其容量 仅下降了 $3.17 \%$. 证明该球形复合材料具有良好的导电 性, 优秀的倍率性能和循环稳定性.

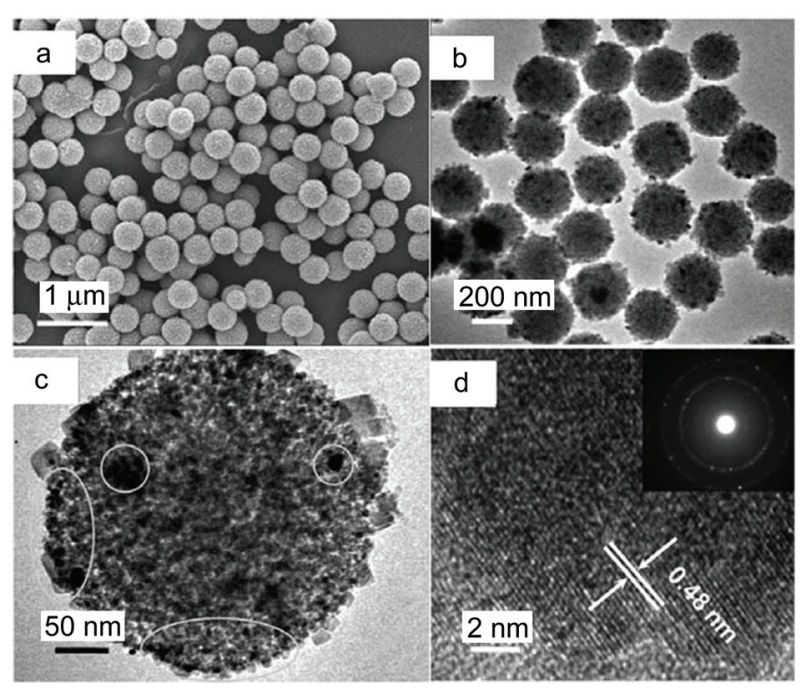

图 2 多孔球形 $\mathrm{Au} / \mathrm{Li}_{4} \mathrm{Ti}_{5} \mathrm{O}_{12}$ 的(a) SEM, (b, c) TEM 和(d) HRTEM 图 ${ }^{[32]}$ Figure 2 Typical (a) SEM, (b, c) TEM, and (d) HRTEM images of the mesoporous $\mathrm{Au} / \mathrm{Li}_{4} \mathrm{Ti}_{5} \mathrm{O}_{12}$ spheres $^{[32]}$

相对以上方法, 溶胶凝胶法制得的 $\mathrm{Li}_{4} \mathrm{Ti}_{5} \mathrm{O}_{12}$ 均匀性 好, 化学计量比也可精确控制, 但也面临着成本高、易 团聚的制约. 为了解决团聚的问题, 王等 ${ }^{[33]}$ 以月桂酸为 分散剂, 无水乙醇为溶剂, 利用无水溶胶凝胶法合成高 分散的 $\mathrm{Li}_{4} \mathrm{Ti}_{5} \mathrm{O}_{12}$, 颗粒尺寸在 $120 \sim 275 \mathrm{~nm}$ 之间, 基本 无团聚, 具有较好的分散性. 其 $0.1 \mathrm{C}$ 下的首次放电比 容量高达 $229.1 \mathrm{mAh}^{\circ} \mathrm{g}^{-1}$, 循环 50 次后仍有 $192.7 \mathrm{mAh} \cdot$ $\mathrm{g}^{-1}$, 均超过了其理论比容量, 这可能是纳米颗粒良好 的分散性, 使其还原了更多的 $\mathrm{Ti}^{4+}$, 也可能与电解液的 不可逆分解或者导电剂乙炔黑的不可逆嵌锂等相关.

Gao 等 ${ }^{[34]}$ 利用内凝胶法制得的球形 $\mathrm{Li}_{4} \mathrm{Ti}_{5} \mathrm{O}_{12}$ 产物 粒径则相对较大, 分布在 $2 \sim 6 \mu \mathrm{m}$ 之间, 振实密度达 $1.64 \mathrm{~g} \cdot \mathrm{cm}^{-3}$, 明显优于非球形 $\mathrm{Li}_{4} \mathrm{Ti}_{5} \mathrm{O}_{12}$ 材料. 0.08 $\mathrm{mA} \cdot \mathrm{cm}^{-2}$ 电流密度下首次放电量为 $161 \mathrm{mAh} \cdot \mathrm{g}^{-1}$, 循环 100 次后保持在 $140 \mathrm{mAh} \cdot \mathrm{g}^{-1}$, 显示了良好的循环性.

综上所述, 球形颗粒能够显著提高 $\mathrm{Li}_{4} \mathrm{Ti}_{5} \mathrm{O}_{12}$ 的振实 密度, 其制备方法中以喷雾干燥法和水热合成法最为常 见，也更易控制产物的形貌和尺度.

\section{3 多孔及中空多孔结构}

一方面, 球形颗粒之间接触紧密, 具有较高的体积 容量，但另一方面由于其颗粒间的接触电阻随温度的降 低而急剧升高, 使得其在低温下的电化学性能不如较大 颗粒的 $\mathrm{Li}_{4} \mathrm{Ti}_{5} \mathrm{O}_{12}{ }^{[35]}$. 研究表明, 多孔结构的 $\mathrm{Li}_{4} \mathrm{Ti}_{5} \mathrm{O}_{12}$ 克服了球形粒径受温度影响大和活性过高的缺点，通过 改变工艺参数可实现孔径可调, 合成产物具有较高的比 表面积, 与电解液的接触面积大等优点, 有利于 $\mathrm{Li}^{+}$的 快速嵌入和脱出，可以显著提高 $\mathrm{Li}_{4} \mathrm{Ti}_{5} \mathrm{O}_{12}$ 的倍率性能和 循环稳定性 ${ }^{[36 \sim 44]}$.

固相法操作简单, 而辅之以高能球磨法, 能够得到 精细均匀的产物. Lai 等 ${ }^{[36]}$ 利用该方法合成的精细介孔 结构 $\mathrm{Li}_{4} \mathrm{Ti}_{5} \mathrm{O}_{12}$ 产品直径只有 $8 \mathrm{~nm}$, 颗粒内部布有许多 大小为 $1.9 \mathrm{~nm}$ 和 $3.8 \mathrm{~nm}$ 的孔道. 其在 $10 \mathrm{C}$ 下的初始放 电量为 $174.5 \mathrm{mAh} \cdot \mathrm{g}^{-1}$, 循环 50 次后容量保持在 143.4 $\mathrm{mAh} \cdot \mathrm{g}^{-1}$.

多孔可有效提高其倍率性，为了进一步提高材料的 电导率, 高等 ${ }^{[37]}$ 经喷雾干燥法和高温炦烧制得了包覆 有纳米碳层的多孔球形钛酸锂材料, 并对其电化学性能 进行了研究. 经分析, 产物粒径约为 $5 \mu \mathrm{m}$, 表面分布有 众多孔洞, 孔径约为 $3.421 \mathrm{~nm}$. 在 $1.0 \mathrm{C}$ 和 $5.0 \mathrm{C}$ 倍率下, 该材料的首次放电比容量分别为 $168.2 \mathrm{mAh} \cdot \mathrm{g}^{-1}$ 和 153.6 $\mathrm{mAh} \cdot \mathrm{g}^{-1}$, 其中 $5.0 \mathrm{C}$ 下循环 20 次后的容量保持率为 $95.8 \%$ ，显示了较高的倍率容量.

传统的方法合成含碳球形 $\mathrm{Li}_{4} \mathrm{Ti}_{5} \mathrm{O}_{12}$, 往往需要分几 步完成, 而 Guan 等 ${ }^{[38]}$ 利用热分解法经一步合成得到了 多孔碳包覆 $\mathrm{Li}_{4} \mathrm{Ti}_{5} \mathrm{O}_{12}$ 纳米颗粒. 该颗粒直径只有 $20 \mathrm{~nm}$, 碳以小于 $5 \mathrm{~nm}$ 的薄层均匀包覆在 $\mathrm{Li}_{4} \mathrm{Ti}_{5} \mathrm{O}_{12}$ 表面, 而其 平均孔径为 $3.7 \mathrm{~nm}$ 左右. 发现其在 $2 \mathrm{C}$ 倍率下的库伦效 率高达 $99 \%$, 在 $10 \mathrm{C}$ 下首次放电量为 $137 \mathrm{mAh} \cdot \mathrm{g}^{-1}$, 1600 次循环后可逆容量保持在 $107 \mathrm{mAh} \cdot \mathrm{g}^{-1}$, 相对非介 孔 $\mathrm{Li}_{4} \mathrm{Ti}_{5} \mathrm{O}_{12}$ 材料, 具有更优秀的大倍率充放电性能和循 环稳定性.

先通过溶胶凝胶法制备单分散的球形 $\mathrm{TiO}_{2}$, 再合 成 $\mathrm{Li}_{4} \mathrm{Ti}_{5} \mathrm{O}_{12}$, 也是目前合成介孔 $\mathrm{Li}_{4} \mathrm{Ti}_{5} \mathrm{O}_{12}$ 的方法之一. $\mathrm{Lin}$ 等 ${ }^{[39]}$ 将所得介孔 $\mathrm{TiO}_{2}$ 与 $\mathrm{Li}_{2} \mathrm{O}$ 混合炦烧合成了单分 散的介孔钛酸锂材料(如图 3). 经氮吸附/脱附等温曲线 分析, 产物的孔径约为 $3.9 \mathrm{~nm}$. 该产品在 $0.5 \mathrm{C}$ 下的稳 定放电量为 $160 \mathrm{mAh} \cdot \mathrm{g}^{-1}$, 即使是在 $5 \mathrm{C}$ 倍率下, 其可逆 放电量也有超过 $0.5 \mathrm{C}$ 时放电量的一半，接近非介孔结 构 $1 \mathrm{C}$ 倍率下的放电量.

溶剂热法是水热法的发展，相对其它传统合成方 法，该法过程相对简单，形貌可控. Feckl 等 ${ }^{[40]}$ 直接利用 无水溶剂热反应合成了平均孔径为 7 $8 \mathrm{~nm}$ 的纳米多孔 $\mathrm{Li}_{4} \mathrm{Ti}_{5} \mathrm{O}_{12}$. 通过煅烧形成厚度为 $150 \sim 500 \mathrm{~nm}$ 的介孔薄 膜. 分别在 $25,50,100,200,300$ 和 $400 \mathrm{C}$ 进行 10 次循环 后的比容量分别约为 $173,163,151,136,116$ 和 105 $\mathrm{mAh} \cdot \mathrm{g}^{-1}$. 其中, $100 \mathrm{C}$ 下循环 500 次后容量保持率为 


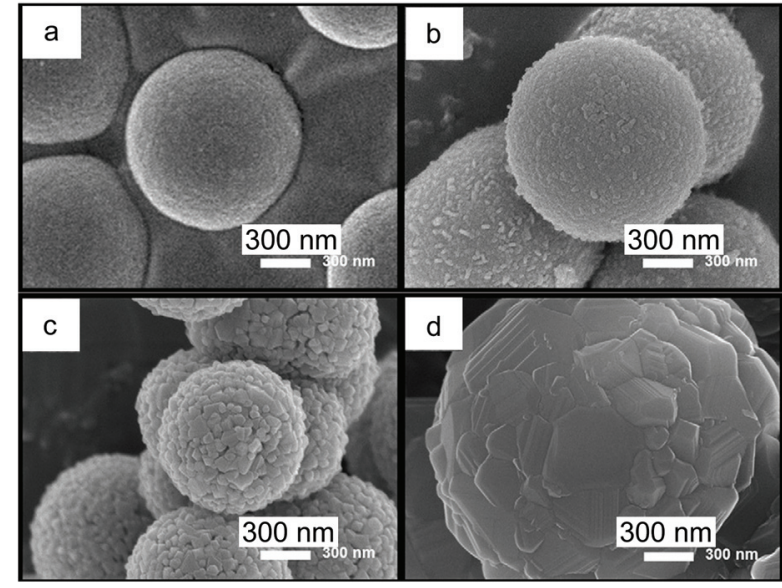

图 3 (a) $\mathrm{TiO}_{2}$ 前驱体, (b) 溶剂热处理后的介孔粉末, (c) 介孔钛酸锂 和(d) 无孔钛酸锂 SEM 图 ${ }^{[39]}$

Figure 3 SEM images of (a) amorphous $\mathrm{TiO}_{2}$ precursor, (b) mesoporous powders after solvothermal process, (c) mesoporous lithium titanate after calcinations and (d) non-porous lithium titanate ${ }^{[39]}$

98\%, 即使循环 1000 次后, 容量保持率依然有 $89 \%$, 展 现出异常优异的倍率性能和极其优秀的循环稳定性.

具有特殊形貌的材料往往存在令人惊喜的结果. 嵌 段共聚物自组装可通过简单调节共聚物的组成、含量等 条件获得特殊形态的 $\mathrm{Li}_{4} \mathrm{Ti}_{5} \mathrm{O}_{12}$ 材料. Kang 等 ${ }^{[41}$ 借此获 得了介孔结构的 $\mathrm{Li}_{4} \mathrm{Ti}_{5} \mathrm{O}_{12}-\mathrm{C}$ 纳米复合物. 该介孔复合物 的孔径为 $20 \mathrm{~nm}$ 左右, 呈有序通道或蠕虫孔状均匀分布 于整个产物颗粒. $10 \mathrm{C}$ 下循环 500 次后其可逆容量保持 在 $115 \mathrm{mAh} \cdot \mathrm{g}^{-1}$, 容量保持率高达 $90 \%$, 显示了优秀的 电化学特性.

中空多孔结构相对简单的多孔结构具有更大的比 表面积和更高的离子流动性, 因而表现出更优秀的大倍 率充放电特性.

中空结构稳定性差, 且不易制备, 目前常用的方法 是模板法. $\mathrm{Yu}$ 等 ${ }^{[42]}$ 以单分散纳米球形 $\mathrm{SiO}_{2}$ 胶体为模板, 无定形 $\mathrm{TiO}_{2}$ 为前驱体, 先利用溶胶凝胶法以 $\mathrm{SiO}_{2}$ 为核 合成核壳结构的 $\mathrm{SiO}_{2}-\mathrm{TiO}_{2}$, 再在 $\mathrm{LiOH}$ 溶液中用一步水 热法除去 $\mathrm{SiO}_{2}$ 后合成了中空多孔的 $\mathrm{Li}_{4} \mathrm{Ti}_{5} \mathrm{O}_{12}$. 通过控制 正四丁基钛酸的量可在 50 200 nm 之间调节壳的厚度, 在 $5 \mathrm{C}$ 和 $10 \mathrm{C}$ 下的可逆放电容量分别为 $128 \mathrm{mAh} \cdot \mathrm{g}^{-1}$ 和 $115 \mathrm{mAh} \cdot \mathrm{g}^{-1}$, 其中 $5 \mathrm{C}$ 下循环 300 次后容量仅损失 了 $12 \%$, 显示了较好的循环性, 而在 $20 \mathrm{C}$ 的高倍率下其 可逆比容量依然保持在 $104 \mathrm{mAh} \cdot \mathrm{g}^{-1}$.

同样, $\mathrm{He}$ 等 ${ }^{[43]}$ 以球形碳作为模板制得了单分散的 中空球形 $\mathrm{Li}_{4} \mathrm{Ti}_{5} \mathrm{O}_{12}$. 所得材料的外径约为 $1.0 \mu \mathrm{m}$, 平均 壁厚 $60 \mathrm{~nm}$, 其表面分布有众多开放的孔(见图 4). 电化 学测试显示, 在 $10 \mathrm{C}$ 的大倍率下的放电比容量为 100 $\mathrm{mAh} \cdot \mathrm{g}^{-1} ; 2 \mathrm{C}$ 下, 连续充放电 200 次后其放电比容量几 乎没有衰退, 稳定在 $150 \mathrm{mAh} \cdot \mathrm{g}^{-1}$.

虽然模板法在中空结构的制备中具有无可比拟的 优越性, 但同时模板法也存在合成过程相对复杂的缺 点, 而 Yang 等 ${ }^{[44]}$ 通过对喷雾干燥法进行研究, 利用该

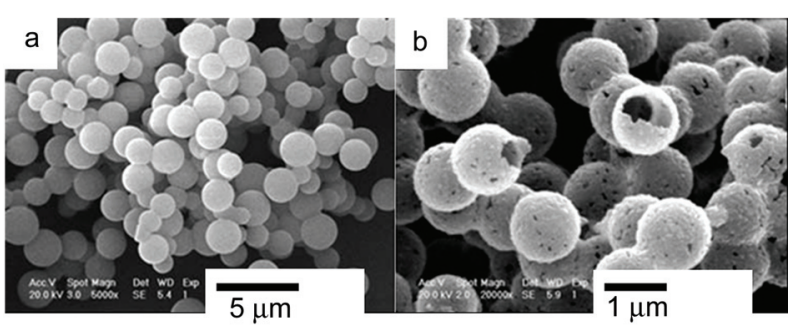

图 4 (a) 碳球和(b) $\mathrm{Li}_{4} \mathrm{Ti}_{5} \mathrm{O}_{12}$ 中空球的 SEM 图 ${ }^{[43]}$

Figure 4 SEM images of (a) carbon spheres and (b) $\mathrm{Li}_{4} \mathrm{Ti}_{5} \mathrm{O}_{12}$ hollow spheres $^{[43]}$

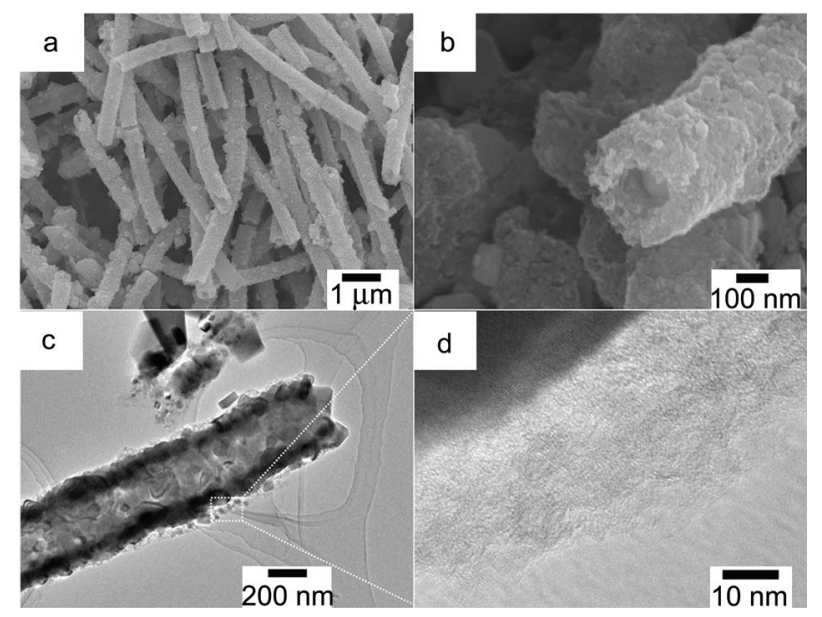

图 5 FE-SEM 图(a) LTO-AC 混合碳纳米管及(b)放大图, TEM 图(c) LTO-AC 混合碳纳米管及(d)表面区域放大图 ${ }^{[46]}$. [原文引用]-由英国皇 家化学学会许可转载.

Figure 5 FE-SEM micrographs of (a) LTO-AC hybrid nanotubes with (b) a magnified image; and TEM micrograph of (c) the LTO-AC hybrid nanotubes and (d) a magnified image of the surface region ${ }^{[46]}$. [Original citation] - Reproduced by permission of The Royal Society of Chemistry.

法和随后的热处理过程与具有高比容量的 $\mathrm{SnO}_{2}$ 合成了 过锂的中空球形 $\mathrm{Li}_{4} \mathrm{Ti}_{5} \mathrm{O}_{12}-\mathrm{SnO}_{2}$ 复合材料. 由于 $\mathrm{SnO}_{2}$ 的 添加, 其在 $170 \mathrm{~mA} \cdot \mathrm{g}^{-1}$ 的电流密度下, 首次放电量为 $439 \mathrm{mAh} \cdot \mathrm{g}^{-1}$, 循环 30 次后容量保持率为 $82 \%$, 这种中 空复合结构相对简单复合的 $\mathrm{Li}_{4} \mathrm{Ti}_{5} \mathrm{O}_{12}-\mathrm{SnO}_{2}{ }^{[45]}$, 在循环 性上有明显提升.

\section{4 一维纳米结构}

尽管球形和多孔结构都各具优点, 但它们对电导率 的提高却相对有限, 而纳米结构材料可有效解决 $\mathrm{Li}_{4} \mathrm{Ti}_{5} \mathrm{O}_{12}$ 电导率低的问题.

一维纳米材料是指向一个方向定向延伸，而其它两 个方向的维度受到抑制的一类材料，包括纳米管、纳米 线、纳米棒、纳米纤维等不同形貌. 由于该结构材料的 轴向长度可达到微米级, 而径向却只有纳米级, 从而可 同时实现提高循环性和离子迁移率的双重作用. 不同一 维纳米结构 $\mathrm{Li}_{4} \mathrm{Ti}_{5} \mathrm{O}_{12}$ 的优点、实验方法、形貌特征、电 化学性能及研究工作亮点见表 1 .

从表 1 可以看出, 静电纺丝技术作为制备一维纳米 材料的最常用技术, 它具有操作简单、可连续生产的优 
表 1 不同一维纳米结构 $\mathrm{Li}_{4} \mathrm{Ti}_{5} \mathrm{O}_{12}$ 的优点、实验方法、形貌特征、电化学性能及研究工作亮点

Table 1 The advantages, experiment methods, morphology characteristics, electrochemical properties and research highlights of different one-dimensional $\mathrm{Li}_{4} \mathrm{Ti}_{5} \mathrm{O}_{12}$ nanostructures

\begin{tabular}{|c|c|c|c|c|c|}
\hline 一维纳米材料 & 优点 & 相关文献 & 实验方法及形貌特征 & 电化学性能 & 工作亮点 \\
\hline 纳米管 & $\begin{array}{l}\mathrm{Li}_{4} \mathrm{Ti}_{5} \mathrm{O}_{12} \text { 纳米管是中空的 } \\
\text { 具有大量内部通道的一 } \\
\text { 维纳米结构材料. 它高的 } \\
\text { 长径比和特殊的中空通 } \\
\text { 道结构, 使其具有较大的 } \\
\text { 比表面积, 能有效提高电 } \\
\text { 解液和活性材料的接触 } \\
\text { 面积, 同时能缩短离子迁 } \\
\text { 移路径, 提高电导性. }\end{array}$ & {$[46]$} & $\begin{array}{l}\text { 原位溶胶凝胶反应结合静 } \\
\text { 电纺丝技术; 制得管径约 } \\
\text { 为 } 250 \mathrm{~nm} \text { 的一维管状 } \\
\mathrm{Li}_{4} \mathrm{Ti}_{5} \mathrm{O}_{12-} \text { 活 性 碳 (LTO- } \\
\mathrm{AC} \text { )复合材料(如图 5). }\end{array}$ & $\begin{array}{l}\text { 作为锂离子电池负极材 } \\
\text { 料, 在 } 100 \sim 4000 \mathrm{~mA} \cdot \\
\mathrm{g}^{-1} \text { 下 的放电容量为 } \\
128 \sim 84 \mathrm{mAh} \cdot \mathrm{g}^{-1} \text {. 作为 } \\
\text { 电容器的负极材料, 能 } \\
\text { 量密度和功率密度分别 } \\
\text { 达到 } 32 \mathrm{Wh} \cdot \mathrm{kg}^{-1} \text { 和 } 6000 \\
\mathrm{~W} \cdot \mathrm{kg}^{-1} \text {. } \\
0.1 \mathrm{C} \text { 时的首次放电比容 } \\
\text { 量为 } 156 \mathrm{mAh} \cdot \mathrm{g}^{-1} \text {, 放电 } \\
\text { 倍率为 } 2 \mathrm{C} \text { 时, 其相对 } \\
0.2 \mathrm{C} \text { 时的放电比容量保 } \\
\text { 持率为 } 93 \% \text {. }\end{array}$ & $\begin{array}{l}\text { 与碳复合形成的复 } \\
\text { 合纳米管, 在锂离子 } \\
\text { 电池系统中, 具有优 } \\
\text { 异的高倍率性能; 在 } \\
\text { 电容器系统中, 具有 } \\
\text { 高的能量密度和功 } \\
\text { 率密度. }\end{array}$ \\
\hline 纳米棒 & $\begin{array}{l}\mathrm{Li}_{4} \mathrm{Ti}_{5} \mathrm{O}_{12} \text { 纳米管虽然具有 } \\
\text { 较高的比表面积和表面 } \\
\text { 活性, 但易与电解液发生 } \\
\text { 副反应, 影响其循环稳定 } \\
\text { 性. 同时, 纳米管的空心 } \\
\text { 结构导致其振实密度低, } \\
\text { 比能量小. 对比纳米管, } \\
\mathrm{Li}_{4} \mathrm{Ti}_{5} \mathrm{O}_{12} \text { 纳米棒拥有较高 } \\
\text { 的振实密度和合适的表 } \\
\text { 面活性, 因而具有比能量 } \\
\text { 高和循环性能好的优势. }\end{array}$ & [49] & $\begin{array}{l}\text { 先利用水热法和熔融盐离 } \\
\text { 子交换法制备了钛酸锂中 } \\
\text { 间体, 经热处理获得纳米 } \\
\text { 棒状 } \mathrm{Li}_{4} \mathrm{Ti}_{5} \mathrm{O}_{12} \text {. }\end{array}$ & $\begin{array}{l}\text { 因产物中存在贫锂的锐 } \\
\text { 钛矿 } \mathrm{Li}_{x} \mathrm{TiO}_{2} \text {, 所以在 } 50 \\
\mathrm{~mA} \cdot \mathrm{g}^{-1} \text { 的电流密度下的 } \\
\text { 初始放电量超过了其比 } \\
\text { 容量, 为 } 193.1 \mathrm{mAh} \cdot \mathrm{g}^{-1} \text {. } \\
\text { 而循环 } 80 \text { 次后, 比容量 } \\
\text { 依然有 } 162.8 \mathrm{mAh} \cdot \mathrm{g}^{-1} \text {. } \\
\text { 在 } 50 \mathrm{~mA} \cdot \mathrm{g}^{-1} \text { 下的初始放 } \\
\text { 电量为 } 156.2 \mathrm{mAh \cdot g}{ }^{-1} \text {, } \\
\text { 循环 } 100 \text { 次后, 容量保持 } \\
\text { 率为 } 95 \% \text {. 在 } 1600 \mathrm{~mA} \cdot \\
\mathrm{g}^{-1} \text { 的大电流时, 初始放 } \\
\text { 电容量仍有 } 133.8 \mathrm{mAh} \cdot \\
\mathrm{g}^{-1} \text {. }\end{array}$ & $\begin{array}{l}50 \mathrm{~mA} \cdot \mathrm{g}^{-1} \text { 下 } 193.1 \\
\mathrm{mAh} \cdot \mathrm{g}^{-1} \text { 的放电量显 } \\
\text { 示了高的比容量. }\end{array}$ \\
\hline \multirow{3}{*}{ 纳米线/纤维 } & \multirow{3}{*}{$\begin{array}{l}\mathrm{Li}_{4} \mathrm{Ti}_{5} \mathrm{O}_{12} \text { 纳米线和纳米纤 } \\
\text { 维的直径能够达到几个 } \\
\text { 纳米, 可以大大缩短锂离 } \\
\text { 子在充放电过程中的迁 } \\
\text { 移距离, 提高比容量. 而 } \\
\text { 其纵向的延续性则保证 } \\
\text { 了 } \mathrm{Li}_{4} \mathrm{Ti}_{5} \mathrm{O}_{12} \text { 的高倍率表 } \\
\text { 现性和循环稳定性. }\end{array}$} & {$[50]$} & $\begin{array}{l}\text { 静电纺丝法; 合成了一维 } \\
\text { 多孔 } \mathrm{Li}_{4} \mathrm{Ti}_{5} \mathrm{O}_{12} \text { 纤维, 平均 } \\
\text { 直径约为 } 230 \mathrm{~nm} .\end{array}$ & $\begin{array}{l}20,40 \text { 和 } 60 \mathrm{C} \text { 下的放电 } \\
\text { 比容量 分别为 } 123.4 \text {, } \\
108.8 \text { 和 } 90.4 \mathrm{mAh}^{-1} \text {. }\end{array}$ & $\begin{array}{l}20 \mathrm{C} \text { 下连续充放电 } \\
300 \text { 次后可逆容量依 } \\
\text { 然有 } 120.1 \mathrm{mAh} \cdot \mathrm{g}^{-1} \text {, } \\
\text { 显示了优异的大倍 } \\
\text { 率循环稳定性. }\end{array}$ \\
\hline & & {$[51]$} & $\begin{array}{l}\text { 以聚乙烯吡咯烷酮(PVP) } \\
\text { 作为调节剂, 采用静电纺 } \\
\text { 丝法; 在聚乙烯吡咯烷酮 } \\
\text { 的质量比为 } 6 \% \text { 时所得纳 } \\
\text { 米 } \mathrm{Li}_{4} \mathrm{Ti}_{5} \mathrm{O}_{12} \text { 纤维具有规则 } \\
\text { 的一维形貌, 平均直径在 } \\
200 \sim 600 \mathrm{~nm} \text { 之间(如图 6). }\end{array}$ & $\begin{array}{l}10 \mathrm{C} \text { 下的首次放电量为 } \\
138 \mathrm{mAh} \cdot \mathrm{g}^{-1}, 0.1 \mathrm{C} \text { 下充 } \\
\text { 放电循环 } 50 \text { 次后其容量 } \\
\text { 几乎没有变化. }\end{array}$ & $\begin{array}{l}\text { 通过控制聚乙烯吡 } \\
\text { 咯烷酮的量可调节 } \\
\text { 纤维素的直径, 实现 } \\
\text { 可控合成. }\end{array}$ \\
\hline & & {$[52]$} & $\begin{array}{l}\text { 采用碱性水热处理结合离 } \\
\text { 子交换法, 直接在 } \mathrm{Ti} \text { 䇴上 } \\
\text { 自组装形成线径为 } 90 \mathrm{~nm} \text {, } \\
\text { 长度约 } 8 \mu \mathrm{m} \text { 的纳米线状 } \\
\mathrm{Li}_{4} \mathrm{Ti}_{5} \mathrm{O}_{12} .\end{array}$ & $\begin{array}{l}30 \mathrm{C} \text { 时其放电比容量为 } \\
121 \mathrm{mAh} \cdot \mathrm{g}^{-1} \text {. 而在 } 5 \mathrm{C} \\
\text { 倍率下循环 } 100 \text { 次后的 } \\
\text { 放电比容量仅损失 } 5 \% .\end{array}$ & $\begin{array}{l}\text { 在纳米线表面还附 } \\
\text { 有纳米大 小 的 } \\
\mathrm{Li}_{4} \mathrm{Ti}_{5} \mathrm{O}_{12} \text { 颗粒, 这可 } \\
\text { 大大增加其比表面 } \\
\text { 积, 有利于比容量的 } \\
\text { 提高. }\end{array}$ \\
\hline
\end{tabular}

点, 但其对溶液浓度、电场强度、给料速度等的要求也 较高. 因此，寻找一个更加廉价、方便的制备方法成为 未来一维纳米材料应用的挑战之一. 另外, 如何实现纳 米尺寸可控和解决堆积过程中的团聚问题, 也是一维纳 米材料面临的另两大难点.

\section{5 二维纳米结构}

与一维纳米材料不同, 二维纳米材料是由纳米晶粒 构成的单层或多层的薄层结构材料, 其在两个维度上具 有延伸性. 该结构表面积大，离子迁移路径短，同时也 可直接在表面镶嵌其它高电导性材料对 $\mathrm{Li}_{4} \mathrm{Ti}_{5} \mathrm{O}_{12}$ 进行 


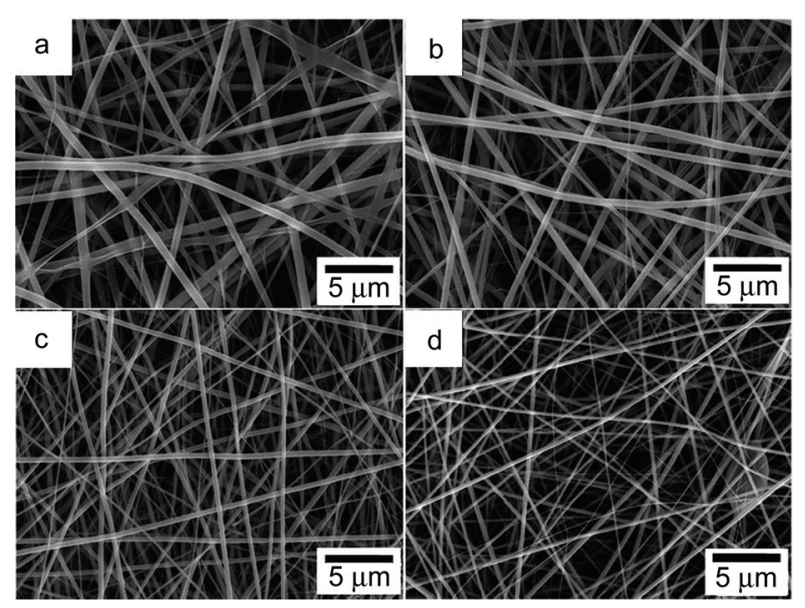

图 6 不同质量比 $(5 \sim 8 \mathrm{wt} \%)$ 的 PVP 得到的 $\mathrm{PVP} /$ 无机复合纳米纤维 SEM 图: (a) 8, (b) 7, (c) 6 和(d) $5^{[51]}$. [原文引用]-由英国皇家化学学会 许可转载.

Figure 6 SEM images of PVP/inorganic composite nanofibers that were electrospun from a mixture of PVP and inorganic precursors solved in ethanol. The weight ratio of PVP in the solution varied in the range of $5 \sim$ $8 \mathrm{wt} \%$ : (a) 8 , (b) 7, (c) 6 and (d) $5^{[51]}$. [Original citation] - Reproduced by permission of The Royal Society of Chemistry.

改性, 具有广泛的应用前景. 二维纳米 $\mathrm{Li}_{4} \mathrm{Ti}_{5} \mathrm{O}_{12}$ 材料主 要包括纳米片, 纳米薄膜等. 不同二维纳米结构 $\mathrm{Li}_{4} \mathrm{Ti}_{5} \mathrm{O}_{12}$ 的优点、实验方法、电化学性能及研究工作亮 点见表 2 .

从表 2 的实验方法可以看出, 脉冲激光沉积法是目 前制备纳米片和薄膜的常规方法, 具有反应过程迅速、 反应温度低、膜的生长取向可控的优点, 已成为二维纳 米结构 $\mathrm{Li}_{4} \mathrm{Ti}_{5} \mathrm{O}_{12}$ 最常用的合成技术.

另外, 除了制备上表中的单层的薄膜(片)外, 研究 人员还制备了多层 $\mathrm{Li}_{4} \mathrm{Ti}_{5} \mathrm{O}_{12}$ 薄膜, 并对其相关电化学性 能进行了研究. 例如 Mani 等 ${ }^{[62]}$ 通过无模板溶胶凝胶法 在不同的焳烧温度下合成了多层 $\mathrm{Li}_{4} \mathrm{Ti}_{5} \mathrm{O}_{12}$ 复合物薄膜. 经SEM观察, 该平面薄膜表面长有突出的刺, 这些刺聚 集形成连续的网络结构而使表面粗楉, 这增加了其比表 面积, 从而有利于比容量的提高.

\section{6 三维纳米结构}

不同于一维和二维纳米结构, 三维纳米结构在空间 上具有可向四周任意扩散的特性, 但受制备条件苛刻的 影响, 因此目前关于三维纳米结构 $\mathrm{Li}_{4} \mathrm{Ti}_{5} \mathrm{O}_{12}$ 材料的报道 不多.

通过模板法制备的材料具有不易团聚的优点, 因而 目前三维纳米结构的合成多用此法. 同时, 实验过程中 因采用不同的模板, 所以制备的 $\mathrm{Li}_{4} \mathrm{Ti}_{5} \mathrm{O}_{12}$ 性能也不尽相 同.

Woo 等 ${ }^{[63]}$ 通过由直径为 $1 \mu \mathrm{m}$ 的单分散聚苯乙烯组 成的胶体晶体为模板, 制备出 $80 \mu \mathrm{m}$ 厚的三维有序多孔 $\mathrm{Li}_{4} \mathrm{Ti}_{5} \mathrm{O}_{12}$ 薄膜状负极材料. 其在 $0.1 \mathrm{C}$ 下的首次放电量 为 $159 \mathrm{mAh} \cdot \mathrm{g}^{-1}$, 而在 $1 \mathrm{C}$ 下循环 100 次后放电量几乎
没有下降, 稳定的三维结构和产物中大量互相连通的微 孔，使其显示出较高的比容量和理想的循环稳定性.

Sorensen 等 ${ }^{[64]}$ 则通过聚甲基丙烯酸甲酯胶体晶体 为模板, 金属有机溶液为前驱体, 得到三维有序的介孔 $\mathrm{Li}_{4} \mathrm{Ti}_{5} \mathrm{O}_{12}$ 材料, 并研究了填充率和内壁厚度对材料性能 的影响. 当填充率为 $75 \%$ 时, $0.63 \mathrm{~mA} \cdot \mathrm{cm}^{-2}$ 下 $\mathrm{Li}_{4} \mathrm{Ti}_{5} \mathrm{O}_{12}$ 容量稳定在 $155 \mathrm{mAh} \cdot \mathrm{g}^{-1}$, 相比 $0.1 \mathrm{~mA} \cdot \mathrm{cm}^{-2}$ 电流下的 比容量减少了 $7 \%$.

令人惊奇的是，除了以人工合成的胶体晶体为模板 外, Choi 等 ${ }^{[65]}$ 利用可伸缩的天然棉花为模板, 合成了由 $100 \sim 300 \mathrm{~nm}$ 大小的一次颗粒组成的三维多孔结构 $\mathrm{Li}_{4} \mathrm{Ti}_{5} \mathrm{O}_{12}$. 其在 $1 \mathrm{C}$ 和 $10 \mathrm{C}$ 下的放电比容量分别为 160 和 $101 \mathrm{mAh} \cdot \mathrm{g}^{-1}$, 在 $10 \mathrm{C}$ 下循环 100 次后的容量保持率 为 $91 \%$, 具有良好的倍率放电性能.

受印刷术启示, Izumi 等 ${ }^{[66]}$ 采用类似模板法的微印 刷技术制备出了具有立体结构的三维 $\mathrm{Li}_{4} \mathrm{Ti}_{5} \mathrm{O}_{12}$ 负极材 料. 该材料表面呈布满了宽 $70 \mu \mathrm{m}$, 高 $150 \mu \mathrm{m}$ 的线状突 起状，并以 $80 \mu \mathrm{m}$ 的间隔呈规则排列. 充放电测试显示, 在 5 C 下容量保持率为 $90 \%$, 具有良好的稳定性.

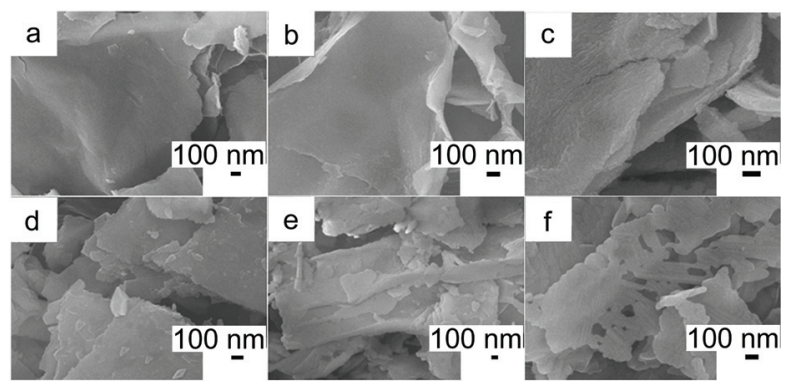

图 7 FE-SEM 图(a)嵌钛 TBA 和(b)不同煅烧温度下的钢酸锂及其派 生物(c) 400 , (d) 500 , (e) 600 和(f) $700{ }^{\circ} \mathrm{C}^{[56]}$

Figure 7 FE-SEM images of (a) TBA-intercalated titanate, (b) lithiated titanate, and its derivatives calcined at (c) 400, (d) 500, (e) 600, and (f) $700{ }^{\circ} \mathrm{C}^{[56]}$

相对于模板法中模板材料的严格选择，溶胶凝胶法 的合成更显简单. Zhang 等 ${ }^{[67]}$ 采用溶胶凝胶法, 以聚偏 二氟乙烯(PVDF)为粘合剂, 制备并研究了不同的碳纳 米纤维 $(\mathrm{CNF})$ 和碳黑 $(\mathrm{CB})$ 添加量对 $\mathrm{Li}_{4} \mathrm{Ti}_{5} \mathrm{O}_{12}$ 形貌和电化 学性能的影响. 结果发现, 当碳纳米纤维质量比为 5.9\% 时形成了由一次纳米小颗粒聚集成的三维刺猬状结构 (如图 8). 其在 $10 \mathrm{C}$ 下循环 500 次后依然有 $122 \mathrm{mAh}$ ・ $\mathrm{g}^{-1}$ 的比容量, $15 \mathrm{C}$ 下仍具有 $123 \mathrm{mAh} \cdot \mathrm{g}^{-1}$ 的比容量, 结 果表明, 该形貌的复合物显著提高了其大倍率充放电性 能, 并表现出优秀的循环稳定性.

综上 $\mathrm{Li}_{4} \mathrm{Ti}_{5} \mathrm{O}_{12}$ 纳米结构的合成与表征，静电纺丝技 术作为一维纳米纤维制备的常用方法, 可纺制超细或纳 米纤维, 有利于大规模生产, 具有广泛的应用前景. 脉 冲激光沉积技术可制备出不同厚度的均匀薄膜, 非常适 合于二维纳米结构 $\mathrm{Li}_{4} \mathrm{Ti}_{5} \mathrm{O}_{12}$ 实验室的研究应用. 模板法 则因其制备过程相对简单、形貌可控、产品均一将在三 维结构制备中占有较大优势. 
表 2 不同二维纳米结构 $\mathrm{Li}_{4} \mathrm{Ti}_{5} \mathrm{O}_{12}$ 的优点、实验方法、电化学性能及研究工作亮点

Table 2 The advantages, experiment methods, morphology characteristics, electrochemical properties and research highlights of different two-dimensional $\mathrm{Li}_{4} \mathrm{Ti}_{5} \mathrm{O}_{12}$ nanostructures

\begin{tabular}{|c|c|c|c|c|c|}
\hline $\begin{array}{l}\text { 二维纳米 } \\
\text { 材料 }\end{array}$ & 优点 & $\begin{array}{l}\text { 相关 } \\
\text { 文献 }\end{array}$ & 实验方法 & 电化学性能 & 工作亮点 \\
\hline \multirow{5}{*}{ 纳米片 } & \multirow{5}{*}{$\begin{array}{l}\text { 纳 米 片 状 } \\
\mathrm{Li}_{4} \mathrm{Ti}_{5} \mathrm{O}_{12} \text { 材料通 } \\
\text { 常只有几十纳 } \\
\text { 米的厚度, 可有 } \\
\text { 效减小电极在 } \\
\text { 大电流下充放 } \\
\text { 电的极化程度, } \\
\text { 提高可逆容量 } \\
\text { 和循环寿命. }\end{array}$} & {$[53]$} & $\begin{array}{l}\text { 水 热 法; 合 成 的二维 } \\
\mathrm{Li}_{4} \mathrm{Ti}_{5} \mathrm{O}_{12} \text { 纳米薄片厚度为 } \\
200 \sim 400 \mathrm{~nm} .\end{array}$ & $\begin{array}{l}\text { 分别在有机电解液和 } \mathrm{S} 114 \mathrm{TFSI} \text { 离子 } \\
\text { 液体电解液中进行了试验. 在有机电 } \\
\text { 解液中, } \mathrm{Li}_{4} \mathrm{Ti}_{5} \mathrm{O}_{12} \text { 纳米片具有较好的 } \\
\text { 电化学性能. } 0.2 \mathrm{C} \text { 和 } 1 \mathrm{C} \text { 倍率下, 首 } \\
\text { 次放电比容量分别为 } 216 \mathrm{mAh} \cdot \mathrm{g}^{-1} \text { 和 } \\
211 \mathrm{mAh} \cdot \mathrm{g}^{-1} \text {, 经 } 50 \text { 次循环, 容量保 } \\
\text { 持率分别为 } 81 \% \text { 和 } 79 \% \text {. }\end{array}$ & $\begin{array}{l}\text { 研究了不同电解液对 } \\
\text { 材料的电化学性能影 } \\
\text { 响, 结果显示在有机 } \\
\text { 电解液中具有更好的 } \\
\text { 电化学性能. }\end{array}$ \\
\hline & & {$[54]$} & $\begin{array}{l}\text { 水热法离子交换过程; 获 } \\
\text { 得 } \mathrm{Li}_{4} \mathrm{Ti}_{5} \mathrm{O}_{12} \text { 纳米片, 并由 } \\
\text { 此聚集呈现微球状. }\end{array}$ & $\begin{array}{l}\text { 当放电倍率为 } 50 \mathrm{C} \text { 时, 循环 } 50 \text { 次后 } \\
\text { 容量保持在 } 131 \mathrm{mAh} \cdot \mathrm{g}^{-1} \text {. }\end{array}$ & $\begin{array}{l}50 \text { C下 } 1 \mathrm{~min} \text { 内可释 } \\
\text { 放充电量的 } 90 \% \text {, 显 } \\
\text { 示了超强的快速充放 } \\
\text { 电能力. }\end{array}$ \\
\hline & & {$[55]$} & $\begin{array}{l}\text { 水热法; 合成的 } \mathrm{Li}_{4} \mathrm{Ti}_{5} \mathrm{O}_{12} \\
\text { 纳米片仅有 } 10 \sim 20 \mathrm{~nm} \\
\text { 厚. }\end{array}$ & $\begin{array}{l}1 \mathrm{C} \text { 下循环 } 100 \text { 次后的放电量稳定在 } \\
160 \mathrm{mAh} \cdot \mathrm{g}^{-1} \text {, 而在 } 10 \mathrm{C} \text { 下循环 } 300 \\
\text { 次后的放电容量依然有 } 120 \mathrm{mAh} \cdot \mathrm{g}^{-1} \text {, } \\
\text { 容量损失 } 10.6 \% .\end{array}$ & $\begin{array}{l}\text { 实现超薄纳米片的合 } \\
\text { 成, 使其具有更优秀 } \\
\text { 的循环性能. }\end{array}$ \\
\hline & & {$[56]$} & $\begin{array}{l}\text { 通过对 } 2 \mathrm{D} \text { 脱落钛酸纳米 } \\
\text { 片的锂化过程和随后不 } \\
\text { 同温度下的煅烧获得纳 } \\
\text { 米片状 } \mathrm{Li}_{4} \mathrm{Ti}_{5} \mathrm{O}_{12} \text { (如图 7). }\end{array}$ & $\begin{array}{l}600{ }^{\circ} \mathrm{C} \text { 锂化温度下获得的 } \mathrm{Li}_{4} \mathrm{Ti}_{5} \mathrm{O}_{12} \text { 纳 } \\
\text { 米片具有相对较高的初始放电量和 } \\
\text { 较好的循环性能, 但首次比容量也只 } \\
\text { 有 } 104 \mathrm{mAh} \cdot \mathrm{g}^{-1} \text {. }\end{array}$ & $\begin{array}{l}\text { 首次通过 } 2 \mathrm{D} \text { 脱落钛 } \\
\text { 酸 纳 米 片 制 备 } \\
\mathrm{Li}_{4} \mathrm{Ti}_{5} \mathrm{O}_{12} \text { 纳米片, 同 } \\
\text { 时烧结温度仅为 } 600 \\
{ }^{\circ} \mathrm{C} \text {. }\end{array}$ \\
\hline & & {$[57]$} & $\begin{array}{l}\text { 以 } \mathrm{Li}_{4} \mathrm{Ti}_{5} \mathrm{O}_{12} \text { 和富含氮的 } \\
\text { 碳为原料, 利用静电纺丝 } \\
\text { 工艺和蒸发聚合技术得 } \\
\text { 到具有二维混合网络结 } \\
\text { 构的 } \mathrm{LTO} / \mathrm{C}-\mathrm{HNS} \text { 混合纳 } \\
\text { 米纤维片, 厚度为 } 35 \mathrm{~nm} \text {. }\end{array}$ & $\begin{array}{l}\text { 作为锂离子电池负极材料, } 100 \mathrm{~mA} \cdot \\
\mathrm{g}^{-1} \text { 下的放电容量达到 } 255 \mathrm{mAh} \cdot \mathrm{g}^{-1} \text {, } \\
4000 \mathrm{~mA} \cdot \mathrm{g}^{-1} \text { 下的放电容量依然有 } \\
135 \mathrm{mAh} \cdot \mathrm{g}^{-1} \text {. 作为电容器的负极材 } \\
\text { 料, 组成的 } \mathrm{LTO} / \mathrm{C}-\mathrm{HNS} \| \mathrm{AC} \text { 系统在 } \\
91 \mathrm{Wh} \cdot \mathrm{kg}^{-1} \text { 和 } 22 \mathrm{Wh} \cdot \mathrm{kg}^{-1} \text { 能量密度 } \\
\text { 下的功率密度分别为 } 50 \mathrm{~W} \cdot \mathrm{kg}^{-1} \text { 和 } \\
4000 \mathrm{~W} \cdot \mathrm{kg}^{-1} \text {. }\end{array}$ & $\begin{array}{l}\text { 与碳材料的复合, 并 } \\
\text { 组成纳米纤维片状结 } \\
\text { 构, 有效增加了比容 } \\
\text { 量, 提高了倍率性. }\end{array}$ \\
\hline \multirow{4}{*}{ 纳米薄膜 } & \multirow{4}{*}{$\begin{array}{l}\text { 薄 膜 状 } \\
\mathrm{Li}_{4} \mathrm{Ti}_{5} \mathrm{O}_{12} \text { 具有和 } \\
\text { 纳米片状相类 } \\
\text { 似的薄层结构, } \\
\text { 但其厚度往往 } \\
\text { 更薄. 这样的二 } \\
\text { 维结构表面平 } \\
\text { 滑, 能够大大简 } \\
\text { 化反应环境, 缩 } \\
\text { 短锂离子脱嵌 } \\
\text { 路径, 而且其独 } \\
\text { 特的形貌特征, } \\
\text { 非常适合作为 } \\
\text { 小型化的锂离 } \\
\text { 子电池的负极. }\end{array}$} & {$[58]$} & $\begin{array}{l}\text { 以 } \mathrm{Pt} / \mathrm{Ti} / \mathrm{SiO}_{2} / \mathrm{Si} \text { 为基底, } \\
\text { 采用脉冲激光沉积技术; } \\
\text { 制得的 } \mathrm{Li}_{4} \mathrm{Ti}_{5} \mathrm{O}_{12} \text { 薄膜厚 } \\
\text { 度为 } 230 \mathrm{~nm} .\end{array}$ & $\begin{array}{l}10 \mu \mathrm{A} \cdot \mathrm{cm}^{-2} \text { 电流密度下的稳定放电比 } \\
\text { 容量为 } 157 \mathrm{mAh} \cdot \mathrm{g}^{-1} \text {, 在 } 60 \mu \mathrm{A} \cdot \mathrm{cm}^{-2} \\
\text { 下的容量为 } 146 \mathrm{mAh} \cdot \mathrm{g}^{-1} \text {. }\end{array}$ & $\begin{array}{l}\text { 小的晶粒尺寸和内含 } \\
\text { 的多孔结构使其具有 } \\
\text { 快速离子扩散能力, } \\
\text { 适合于大电流充放电 } \\
\text { 的应用. }\end{array}$ \\
\hline & & [59] & $\begin{array}{l}\text { 以 } \mathrm{Nb}: \mathrm{SrTiO}_{3} \text { 为基底, 采 } \\
\text { 用脉冲激光沉积技术, 在 } \\
\text { 基底上形成一层厚度为 } \\
27.6 \mathrm{~nm} \text { 的 } \mathrm{Li}_{4} \mathrm{Ti}_{5} \mathrm{O}_{12} \text { 薄膜. }\end{array}$ & $\begin{array}{l}2 \mu \mathrm{A} \cdot \mathrm{cm}^{-2} \text { 下第二次循环时可放出 } \\
217 \mathrm{~mA} \cdot \mathrm{g}^{-1} \text { 的电量, 并通过原位 } \mathrm{X} \text { 射 } \\
\text { 线法对首次循环过程中的 } \mathrm{Li}_{4} \mathrm{Ti}_{5} \mathrm{O}_{12} \\
\text { 表面区域结构进行了研究, 研究表 } \\
\text { 明, 在纳米薄膜的表面可引起锂离子 } \\
\text { 的不可逆过嵌, 导致其具有超过其理 } \\
\text { 论的比容量, 但在循环过程中的不可 } \\
\text { 逆容量明显增加. }\end{array}$ & $\begin{array}{l}\text { 首次充放电过程中表 } \\
\text { 面结构发生的不可逆 } \\
\text { 改变可以使其具有高 } \\
\text { 的比容量, 但导致其 } \\
\text { 在循环过程中的不可 } \\
\text { 逆容量提高. }\end{array}$ \\
\hline & & {$[60]$} & $\begin{array}{l}\text { 经溶胶凝胶法, 煅烧和浸 } \\
\text { 渍等工序后获得均匀透 } \\
\text { 明的膜状 } \mathrm{Li}_{4} \mathrm{Ti}_{5} \mathrm{O}_{12} \text { 电极 } \\
\text { 材料, 薄膜厚度在 } 385 \sim \\
560 \mathrm{~nm} \text { 之间. }\end{array}$ & $\begin{array}{l}17 \mu \mathrm{A} \cdot \mathrm{cm}^{-2} \text { 下其放电量接近 } \mathrm{Li}_{4} \mathrm{Ti}_{5} \mathrm{O}_{12} \\
\text { 的理论值, 循环 } 40 \text { 次后容量几乎没 } \\
\text { 有变化. }\end{array}$ & $\begin{array}{l}\text { 详细讨论了 } \mathrm{Li} / \mathrm{Ti} \text { 比 } \\
\text { 对产物电化学性能的 } \\
\text { 影响. }\end{array}$ \\
\hline & & {$[61]$} & $\begin{array}{l}\text { 通过溶液沉淀和快速退 } \\
\text { 火法制备了厚度仅为 } 140 \\
\mathrm{~nm} \text { 的二维 } \mathrm{Li}_{4} \mathrm{Ti}_{5} \mathrm{O}_{12} \text { 薄膜. }\end{array}$ & $\begin{array}{l}\text { 该二维薄膜在工作电压下的锂脱出容 } \\
\text { 量为 } 59.5 \mu \mathrm{Ah} \cdot \mathrm{cm}^{-2} \cdot \mu \mathrm{m}^{-1} \text {, 库伦效率 } \\
\text { 为 } 95.87 \% \text {. 经 } 50 \text { 次循环后锂脱出容 } \\
\text { 量降低了 } 3.1 \% \text {. }\end{array}$ & $\begin{array}{l}\text { 使用快速退火法制备 } \\
\mathrm{Li}_{4} \mathrm{Ti}_{5} \mathrm{O}_{12} \text { 纳米薄膜. }\end{array}$ \\
\hline
\end{tabular}



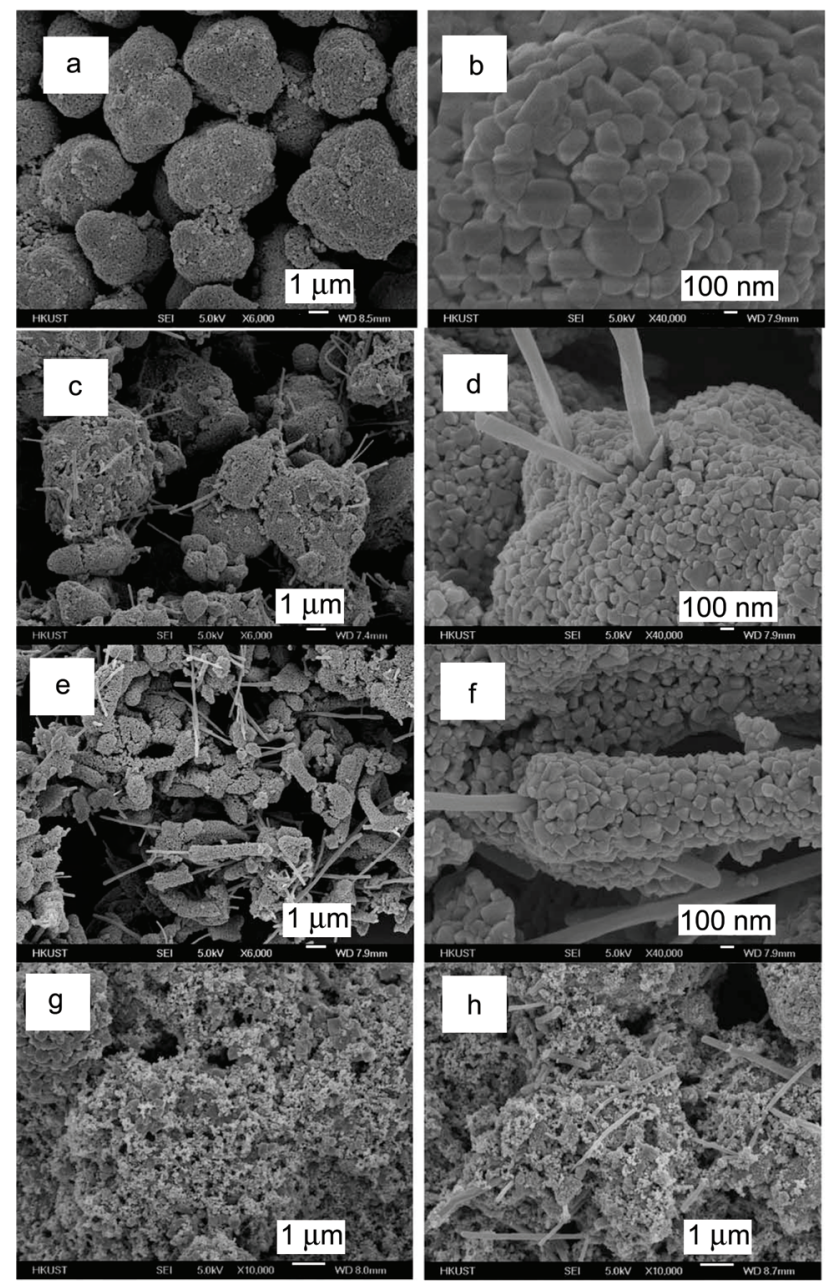

图 8 不同电极材料的 SEM 图(a, b) LTO, (c, d) LTO-CNF (5.9 wt\%), $(\mathrm{e}, \mathrm{f})$ LTO-CNF (11.1 wt\%), (g) LTO-CB (5 wt $\%)$-PVDF 和 (h) LTO-CNF (5.9 wt \%)-CB (5 wt \%)-PVDF ${ }^{[67]}$. [原文引用]-由英国皇家化 学学会许可转载.

Figure 8 SEM images of (a and b) LTO, (c and d) LTO-CNF (5.9 wt $\%$ ), (e and f) LTO-CNF (11.1 wt\%) composites, (g) LTO-CB (5 wt \%)-PVDF and (h) LTO-CNF (5.9 wt\%)-CB (5 wt\%)-PVDF electrode materials ${ }^{[67]}$. [Original citation] - Reproduced by permission of The Royal Society of Chemistry.

\section{7 纳微结构}

$\mathrm{Li}_{4} \mathrm{Ti}_{5} \mathrm{O}_{12}$ 的纳米结构一方面能够大大缩短电子和 离子的扩散路径, 有效提高电极和电解液的接触面积, 有助于材料中活性锂的充分发挥, 从而显著提高其放电 比容量. 但另一方面, 纳米微粒也有表面活性高, 易与 电解液发生副反应的缺点. 为克服其不利因素, 研究者 制备并研究了以纳微结构 $\mathrm{Li}_{4} \mathrm{Ti}_{5} \mathrm{O}_{12}$ 为负极的锂离子电 池电化学性能. 纳微结构是由纳米单元组成的, 而整体 尺度在微米级的一类结构体系, 这类结构体系结合了纳 米结构和微米结构的优点, 能提高锂离子电池的倍率性 能, 延长循环寿命. 作为新型结构的研究热点, 纳微结 构由于其尺寸效应和形貌效应, 越来越受到研究者们的 重视 ${ }^{[68-80]}$.
鉴于球形 $\mathrm{Li}_{4} \mathrm{Ti}_{5} \mathrm{O}_{12}$ 材料具有相对较高的体积能量 密度，且易于制备，球形的纳微结构自然也就成为众多 研究者关注的焦点. Fang 等 ${ }^{[68]}$ 采用水热法和后来的煅烧 合成了 $\mathrm{Li}_{4} \mathrm{Ti}_{5} \mathrm{O}_{12}$ 二次微球. 组成该二次颗粒的一次颗粒 为 30 40 nm 的纳米颗粒; 二次颗粒为高度有序, 平均 粒径为 $1.5 \sim 2 \mu \mathrm{m}$ 的微球. 在 $10 \mathrm{C}$ 下的放电比容量为 $133 \mathrm{mAh} \cdot \mathrm{g}^{-1}$, 甚至在 $60 \mathrm{C}$ 的高倍率下还可放出 80 $\mathrm{mAh} \cdot \mathrm{g}^{-1}$ 的电量.

Tang 等 ${ }^{[69]}$ 通过无模板的水热法和热处理过程, 获 得了纳微结构的 $\mathrm{Li}_{4} \mathrm{Ti}_{5} \mathrm{O}_{12}$ 微球. 该微球由 $20 \mathrm{~nm}$ 的一次 微粒组成, 表面呈现出明显的粗粘状(如图 9). 20 C下循 环 200 次后容量保持在 $125 \mathrm{mAh} \cdot \mathrm{g}^{-1}, 30 \mathrm{C}$ 下的首次放 电比容量为 $114 \mathrm{mAh} \cdot \mathrm{g}^{-1}$, 显示了优秀的高倍率性能和 优良的循环表现性能.
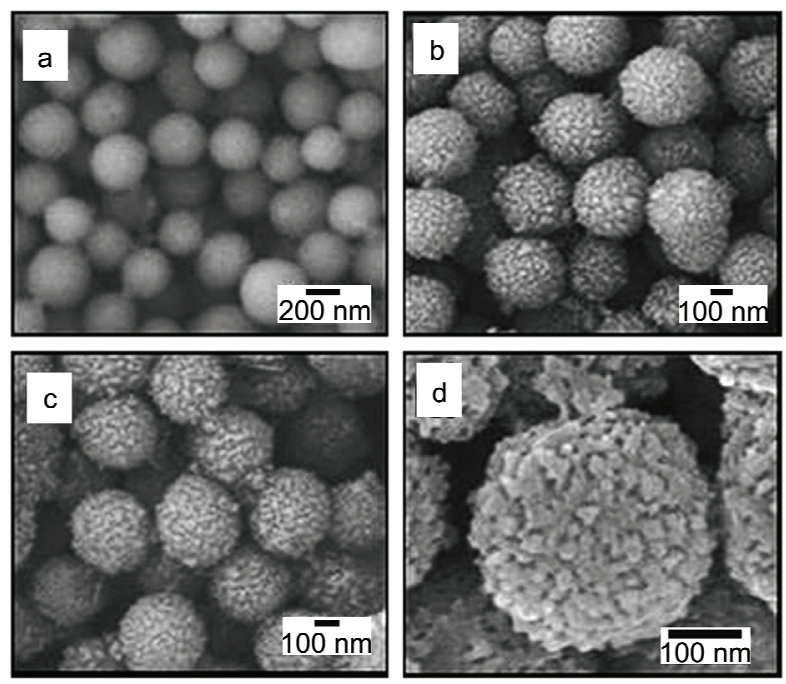

图 $9 \mathrm{SEM}$ 图(a) 球形水合 $\mathrm{TiO}_{2}$ 的, (b) 煅烧前的球形 $\mathrm{Li}_{4} \mathrm{Ti}_{5} \mathrm{O}_{12}$ 和(c, d) $500{ }^{\circ} \mathrm{C}$ 下瑖烧 $1 \mathrm{~h}$ 得到的 $\mathrm{Li}_{4} \mathrm{Ti}_{5} \mathrm{O}_{12}{ }^{[69]}$. [原文引用]-由英国皇家化学学 会许可转载.

Figure 9 SEM images of (a) hydrous titanium oxide spheres, (b) as-synthesized $\mathrm{Li}_{4} \mathrm{Ti}_{5} \mathrm{O}_{12}$ spheres before annealing and (c, d) the spinel $\mathrm{Li}_{4} \mathrm{Ti}_{5} \mathrm{O}_{12}$ spheres after annealing at $500{ }^{\circ} \mathrm{C}$ for $1 \mathrm{~h}^{[69]}$. [Original citation] Reproduced by permission of The Royal Society of Chemistry.

虽然以上的 $\mathrm{Li}_{4} \mathrm{Ti}_{5} \mathrm{O}_{12}$ 球形纳微结构在提高倍率性 和循环性方面卓有成效, 但在解决电导性方面仍有待提 高. 而碳作为掺杂的最佳候选材料, 其既具有较高的电 导性，又可以在一定程度上提高电极材料的比容量. Zhu 等 ${ }^{[70]}$ 通过碳的预包覆过程和喷雾干燥法, 合成了粒 径为 $10 \sim 20 \mu \mathrm{m}$ 的碳包覆 $\mathrm{Li}_{4} \mathrm{Ti}_{5} \mathrm{O}_{12}$ 二次微球颗粒. 该二 次颗粒是由粒径在 $200 \mathrm{~nm}$ 以下的碳包覆 $\mathrm{Li}_{4} \mathrm{Ti}_{5} \mathrm{O}_{12}$ 纳米 一次颗粒组成(如图 10), 二次颗粒中存在大量连通的纳 米孔. 由该二次颗粒组成的负极材料在 $20 \mathrm{C}$ 的高倍率 下相对 $0.2 \mathrm{C}$ 的容量保持率依然有 $79 \%, 1 \mathrm{C}$ 下循环 1000 次后容量也仅衰减 $5 \%$, 具有优异的充放电循环稳定性.

为了进一步提高其倍率性, 研究者还尝试了其它的 制备方法, 并取得了显著的效果，例如 Shen 等 ${ }^{[71]}$ 利用 无模板溶剂热法合成了 $\mathrm{Li}_{4} \mathrm{Ti}_{5} \mathrm{O}_{12}-\mathrm{C}$ 微球. 该产物具有纳 


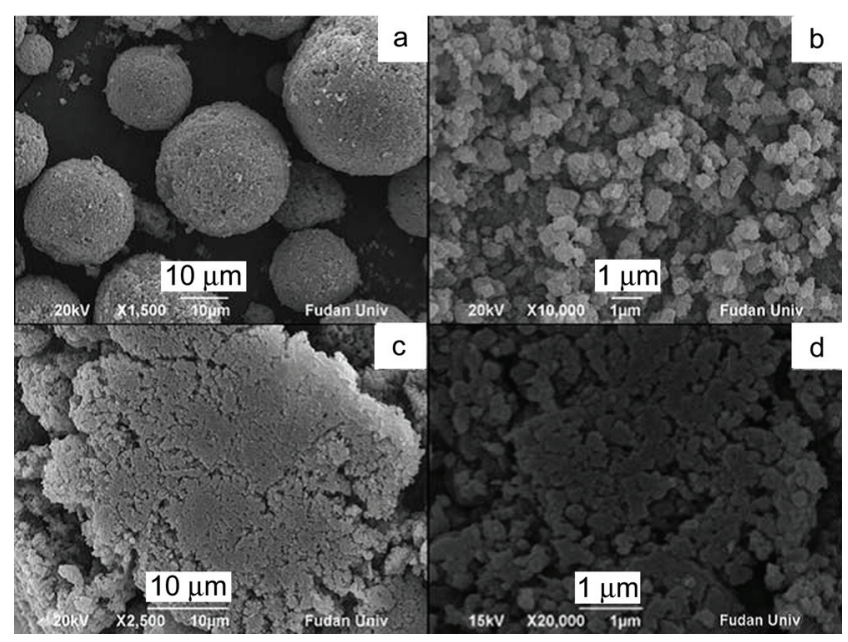

图 10 CN-LTO-NMS 的 SEM 图(a) 微米二次颗粒, (b) 纳米一次颗 粒; (c) CN-LTO-NMS 的截面 SEM 图, (d) 单个微米二次颗粒及其放大 图 ${ }^{[70]}$. [原文引用]-由英国皇家化学学会许可转载.

Figure 10 SEM images of (a) CN-LTO-NMS for the micron-size secondary particles and (b) nanosized primary particles; Cross-section SEM image of (c) one single micron-size secondary particle and (d) its magnified image ${ }^{[0]}$. [Original citation] - Reproduced by permission of The Royal Society of Chemistry

微结构, 是由粒径约 $11 \mathrm{~nm}$ 的纳米颗粒组成的规则球状. 微球粒径分布在 $0.5 \sim 1 \mu \mathrm{m}$ 之间且表面粗粘, 具有较大 的比表面积. 在 $20 \mathrm{C}$ 和 $50 \mathrm{C}$ 下首次循环分别可放出 $125.4 \mathrm{mAh} \cdot \mathrm{g}^{-1}$ 和 $97.1 \mathrm{mAh} \cdot \mathrm{g}^{-1}$ 的电量, 而在后者的倍 率下循环 100 次后容量仅损失 $2.5 \%$, 显示出较低的极化 程度，显著提升了高倍率循环稳定性.

上述方法在高倍率循环稳定性方面取得了可喜的 成果, Jung 等 ${ }^{[2]}$ 则将重点放在提高其能量密度上, 他们 通过水热法和简单固相反应, 在添加碳质量分数为 $5.2 \%$ 时合成了微米尺度球形碳包覆 $\mathrm{Li}_{4} \mathrm{Ti}_{5} \mathrm{O}_{12}$ 复合负极 材料. 所得产物是由 $10 \sim 20 \mathrm{~nm}$ 的一次颗粒组成的二次 颗粒, 粒径约在 $1 \mu \mathrm{m}$ 左右, 振实密度可达 $1.31 \mathrm{~g} \bullet \mathrm{cm}^{-3}$, $10 \mathrm{C}$ 下的首次放电量为 $160 \mathrm{mAh} \cdot \mathrm{g}^{-1}$, 而在 $100 \mathrm{C}$ 的高 倍率下依然可放出 $123 \mathrm{mAh} \cdot \mathrm{g}^{-1}$, 且循环 100 次后容量 几乎没有衰减, 具有优秀的电化学性能.

碳纳米管因其独特的结构和优秀的电学性能, 早已 广泛应用于电极材料的制备之中 ${ }^{[73,74]}$, 而在纳微结构中 的应用目前尚属新意. Shu 等 ${ }^{[75]}$ 用溶胶凝胶法获得 $\mathrm{Li}_{4} \mathrm{Ti}_{5} \mathrm{O}_{12}$ 前驱体后煅烧制得了纳米的 $\mathrm{Li}_{4} \mathrm{Ti}_{5} \mathrm{O}_{12}$ 晶粒, 混 合碳后再经热水解, 在 N-P 合金的催化下生长, 最后形 成了纳微结构的 $\mathrm{Li}_{4} \mathrm{Ti}_{5} \mathrm{O}_{12} / \mathrm{CNT}$ 复合物. 经电化学分析, 该材料在 $10 \mathrm{C}$ 和 $20 \mathrm{C}$ 下的放电比容量分别为 102.6 $\mathrm{mAh} \cdot \mathrm{g}^{-1}$ 和 $73.3 \mathrm{mAh} \cdot \mathrm{g}^{-1}$, 显示了较好的倍率性.

除了在纳微结构中掺杂碳材料以外, 研究者还进行 了其它的尝试. Chen 等 ${ }^{[76]}$ 采用溶剂热法和随后的煅烧 过程, 制得了有缺陷特性的介孔氮化 $\mathrm{Li}_{4} \mathrm{Ti}_{5} \mathrm{O}_{12-y}$ 负极材 料. 所得产物为 $100 \sim 500 \mathrm{~nm}$ 大小的类球状亚微二次颗 粒, 该二次颗粒由粒径约 $15 \sim 25 \mathrm{~nm}$ 的纳米一次颗粒堆 积而成. $20 \mathrm{C}$ 倍率下的首次放电量为 $139 \mathrm{mAh} \cdot \mathrm{g}^{-1}$, 持
续充放电 300 次后，容量保持在 $127 \mathrm{mAh} \cdot \mathrm{g}^{-1}$. 以上结果 表明, 这种含缺陷的纳微介孔结构能有效增强其电子电 导性, 有助于提高大倍率表现性能和循环稳定性.

除了掺杂改性, 外界温度对电池性能的重要性更是 不言而喻, 也是目前影响锂离子电池安全性能的问题之 一. Amine 等 ${ }^{[77]}$ 利用纳米尺寸 $\mathrm{Li}_{4} \mathrm{Ti}_{5} \mathrm{O}_{12}$ 一次颗粒 $(<10$ $\mathrm{nm})$ 通过溶胶凝胶法结合高能球磨合成了大小为 $0.5 \sim 2$ $\mu \mathrm{m}$ 的纳微二次颗粒, 并对该产物的电化学性能和温度 特性进行了研究. 结果表明, 该材料不仅具有较高的放 电比容量, 较长的循环寿命, 在高倍率下工作的安全性 也得到显著提升. 其在 $55{ }^{\circ} \mathrm{C}$ 高温下, $5 \mathrm{C}$ 的放电倍率时 循环 1000 次, 比容量几乎没有衰减, 而相对以碳为负极 的电池则衰退了 $25 \%$. 与此同时, 在 $-30{ }^{\circ} \mathrm{C}$ 低温下进行 的电化学性能测试, 也得到了较为满意的结果.

作为纳微结构的一种, 花样 $\mathrm{Li}_{4} \mathrm{Ti}_{5} \mathrm{O}_{12}$ 展现的阶层结 构能够有效增大活性材料与电解液的接触面积, 缩短离 子传输路径, 提高动力学传输性能, 增强大倍率表现性 能, 具有巨大的潜在研究价值.

Chen 等 ${ }^{[78]}$ 通过热分解过程和随后的热处理过程合 成了由锯齿花样的纳米片组装成的 $\mathrm{Li}_{4} \mathrm{Ti}_{5} \mathrm{O}_{12}$ 微球. 其在 $10000 \mathrm{~mA} \cdot \mathrm{g}^{-1}$ 的高倍率时, 相对于 $200 \mathrm{~mA} \cdot \mathrm{g}^{-1}$ 电流下 的容量保持率依然有 $76 \%$, 且在该大电流强度下循环 200 次后, 其放电比容量仍然保持在 $132 \mathrm{mAh} \cdot \mathrm{g}^{-1}$.

纳米片具有高的比表面积和短的 $\mathrm{Li}^{+}$迁移路径, 而 球形又可弥补前者振实密度低的不足, 因此 Milica 等 ${ }^{[79]}$ 采用水热法并随后在 $400{ }^{\circ} \mathrm{C}$ 下㷽烧获得了由纳米片组 成的花样 $\mathrm{Li}_{4} \mathrm{Ti}_{5} \mathrm{O}_{12}$ 微球和含碳质量分数为 $3 \%$ 的 $\mathrm{Li}_{4} \mathrm{Ti}_{5} \mathrm{O}_{12}-\mathrm{C}$ 微球, 这两种微球分别是由厚度约 $50 \sim 80$ $\mathrm{nm}$ 和 $80 \sim 100 \mathrm{~nm}$ 的纳米片组成(如图 11). 在电导率上, 含碳 $\mathrm{Li}_{4} \mathrm{Ti}_{5} \mathrm{O}_{12}$ 微球 $\left(5.5 \times 10^{-5} \mathrm{~cm}^{2} \cdot \mathrm{s}^{-1}\right)$ 较无碳 $\mathrm{Li}_{4} \mathrm{Ti}_{5} \mathrm{O}_{12}$ 微球 $\left(3.5 \times 10^{-8} \mathrm{~cm}^{2} \cdot \mathrm{s}^{-1}\right)$ 有巨大提升, 相对纯相 $\mathrm{Li}_{4} \mathrm{Ti}_{5} \mathrm{O}_{12}, \mathrm{Li}_{4} \mathrm{Ti}_{5} \mathrm{O}_{12}-\mathrm{C}$ 复合材料在 $5 \mathrm{C}$ 和 $10 \mathrm{C}$ 下的首次 放电量为 $201 \mathrm{mAh} \cdot \mathrm{g}^{-1}$ 和 $203 \mathrm{mAh} \cdot \mathrm{g}^{-1}$, 但其不可逆容 量相对较高, 循环 50 次后分别降为 $161 \mathrm{mAh}^{-1} \mathrm{~g}^{-1}$ 和 150 $\mathrm{mAh} \cdot \mathrm{g}^{-1}$.

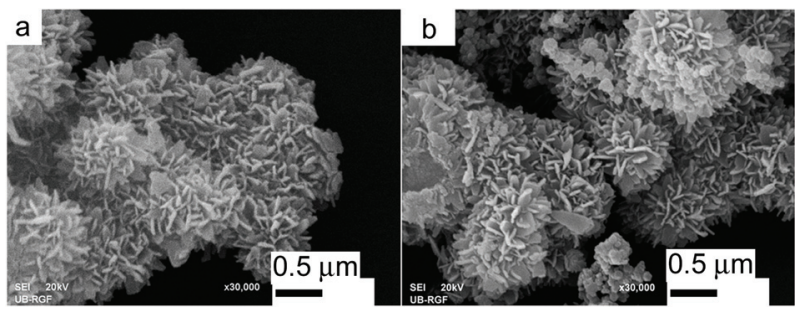

图 11 (a) 纯相 $\mathrm{Li}_{4} \mathrm{Ti}_{5} \mathrm{O}_{12}$ 花样颗粒的 SEM 图; (b) LTO/C 花样颗粒的 SEM 图 ${ }^{[79]}$

Figure 11 SEM images of (a) pure LTO flower-like particles and (b) LTO/C flower-like particles ${ }^{[79]}$

除了形成花样 $\mathrm{Li}_{4} \mathrm{Ti}_{5} \mathrm{O}_{12}-\mathrm{C}$ 微球外, $\mathrm{Liu}$ 等 ${ }^{[80]}$ 利用原 子沉积技术直接在 $\mathrm{Li}_{4} \mathrm{Ti}_{5} \mathrm{O}_{12}$ 电极上沉积 $\mathrm{ZrO}_{2}$ 合成了 $\mathrm{Li}_{4} \mathrm{Ti}_{5} \mathrm{O}_{12}-\mathrm{ZrO}_{2}$ 微球. 通过控制原子沉积循环次数, 实现 
在纳米水平上调整纳米片厚度. 研究证明, 在循环次数 为 1,2 和 5 时所得的三种产物均具有较好的电化学性能. 同时, $\mathrm{ZrO}_{2}$ 的加入也可增加其比容量, 三种产物在 200 $\mathrm{mA} \cdot \mathrm{g}^{-1}$ 下的首次放电容量分别为 330,343 和 $350 \mathrm{mAh} \cdot$ $\mathrm{g}^{-1}$ (充放电电压范围为 $0.1 \sim 2.5 \mathrm{~V}$, 因此超过其理论比 容量). 但由于在低电位下易形成 SEI 膜, 使得其在循环 过程中不可逆损失较大, 循环 100 次后, 三种材料的容 量保持率均在 $60 \%$ 左右. 而在 $1600 \mathrm{~mA} \cdot \mathrm{g}^{-1}$ 高密度电流 下三者的放电比容量分别为 103,101 和 $106 \mathrm{mAh} \cdot \mathrm{g}^{-1}$, 其倍率性也得到了一定提升.

\section{8 核壳结构}

众所周之, 与石墨负极材料相比, $\mathrm{Li}_{4} \mathrm{Ti}_{5} \mathrm{O}_{12}$ 的能量 密度过低. 上述球形、多孔、纳米及纳微结构的形貌改 进虽然可以一定程度上提高其电导率和循环性, 但无法 大幅提高 $\mathrm{Li}_{4} \mathrm{Ti}_{5} \mathrm{O}_{12}$ 的放电容量. 为了提高 $\mathrm{Li}_{4} \mathrm{Ti}_{5} \mathrm{O}_{12}$ 的放 电容量, 多数研究者对 $\mathrm{Li}_{4} \mathrm{Ti}_{5} \mathrm{O}_{12}$ 材料进行了掺杂改性, 但掺杂一是可能会引起 $\mathrm{Li}_{4} \mathrm{Ti}_{5} \mathrm{O}_{12}$ 的结构改变, 从而影响 其循环性, 二是有些掺杂材料(如 $\mathrm{Sn}, \mathrm{SnO}_{2}$ 等)在循环过 程中会产生体积膨胀, 影响电池寿命, 为此核壳结构的 $\mathrm{Li}_{4} \mathrm{Ti}_{5} \mathrm{O}_{12}$ 复合负极材料进入研究者的视野. 核壳复合材 料采用双层或多层结构, 各层间留有中空腔体, 在内部 和外部分别富集不同成分, 既可实现核与壳功能的复合 与互补, 又可缓解因结构改变和体积膨胀带来的循环性 差的不足.

碳材料由于具有电导率高、灵活性好、易制备和低 成本等优点, 已成为 $\mathrm{Li}_{4} \mathrm{Ti}_{5} \mathrm{O}_{12}$ 材料的最佳包覆物 质 ${ }^{[81,82,84]}$.

Shen 等 ${ }^{[81]}$ 利用固相法, 以乙酰丙酮氧钛为钛源和 碳源, $\mathrm{Li}_{2} \mathrm{CO}_{3}$ 为锂源, 通过原位直接生成碳合成了核壳 结构的 $\mathrm{Li}_{4} \mathrm{Ti}_{5} \mathrm{O}_{12} / \mathrm{C}$ 复合材料. 结果显示, 纳米颗粒的碳 均匀包覆在 $\mathrm{Li}_{4} \mathrm{Ti}_{5} \mathrm{O}_{12}$ 核的周围(如图 12), 在 $0.2 \mathrm{C}$ 时的 初始放电比容量为 $161 \mathrm{mAh} \cdot \mathrm{g}^{-1}$, 在 $60 \mathrm{C}$ 和 $90 \mathrm{C}$ 的大倍 率放电条件下, 相对 $0.2 \mathrm{C}$ 时的放电量比率分别为 $64 \%$ 和 $53 \%$. 而在 $10 \mathrm{C}$ 的高倍率下循环 1000 次后, 容量保 持率高达 $95 \%$, 容量损失极小, 显示了高的倍率性能和 良好的循环稳定性.

采用不同的碳源和合成方法对所得材料的结构和 碳层的厚度会产生不同的影响, 进而可影响其电化学性 能. Nugroho 等 ${ }^{[82]}$ 以油胺作为碳源, 采用超临界醇路线 合成核壳纳米复合前驱体，随后在惰性气氛下瑖烧获得 了以 $\mathrm{Li}_{4} \mathrm{Ti}_{5} \mathrm{O}_{12}$ 为核, 碳为壳的核壳结构复合材料. 其中 $\mathrm{Li}_{4} \mathrm{Ti}_{5} \mathrm{O}_{12}$ 核尺寸约为 $5 \sim 15 \mathrm{~nm}$, 碳壳则以 $0.7 \sim 2.3 \mathrm{~nm}$ 的薄层包覆在 $\mathrm{Li}_{4} \mathrm{Ti}_{5} \mathrm{O}_{12}$ 周围, 相对上述 Shen 等 ${ }^{[81]}$ 所得 产物，该材料具有更小的颗粒尺寸和更薄的碳层，在 1 $\mathrm{C}$ 下循环 250 次后容量保持在 $154.6 \mathrm{mAh} \cdot \mathrm{g}^{-1}$, 容量保持 率为 $89 \%$. 而在 $20 \mathrm{C}$ 和 $50 \mathrm{C}$ 的高倍率下的首次放电量 分别为 $139.0 \mathrm{mAh} \cdot \mathrm{g}^{-1}$ 和 $101.0 \mathrm{mAh} \cdot \mathrm{g}^{-1}$, 相对具有更优

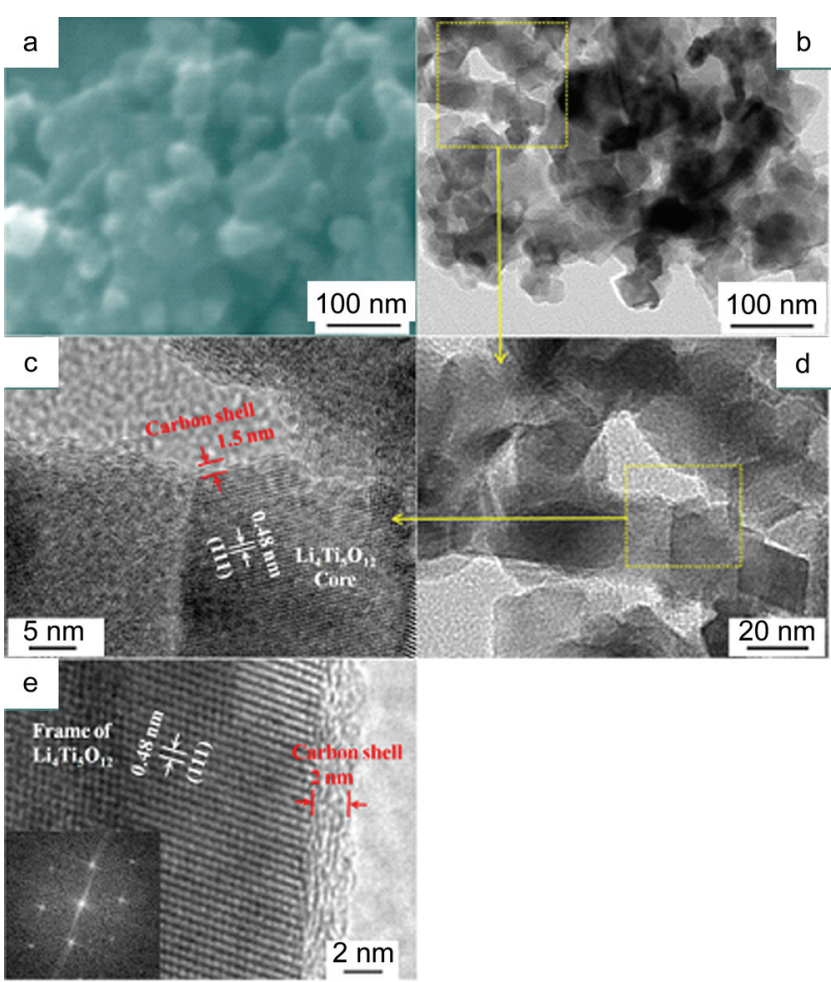

图 12 核壳结构 N-LTO/C 纳米复合物图 $(a)$ SEM, $(b \sim e)$ TEM $^{[81]}$

Figure 12 Typical (a) SEM and $(b \sim$ e) TEM images of the N-LTO/C core-shell nanocomposite ${ }^{[81]}$

秀的高倍率性能.

由于锐钛矿 $\mathrm{TiO}_{2}$ 较高的理论容量 $\left(335 \mathrm{mAh} \bullet \mathrm{g}^{-1}{ }^{[83]}\right)$, Wang 等 ${ }^{[84]}$ 通过溶剂热法制备了两相 $\mathrm{Li}_{4} \mathrm{Ti}_{5} \mathrm{O}_{12}-\mathrm{TiO}_{2}$ 纳 米复合前驱体, 然后以庶糖为碳源, 在高温下反应得到 了核壳结构的碳包覆 $\mathrm{Li}_{4} \mathrm{Ti}_{5} \mathrm{O}_{12}-\mathrm{TiO}_{2}$ 复合产物. 经 $\mathrm{SEM}$ 分析, 碳层以 $5 \mathrm{~nm}$ 的厚度均匀包覆在 $\mathrm{Li}_{4} \mathrm{Ti}_{5} \mathrm{O}_{12}-\mathrm{TiO}_{2}$ 核 的周围, 整个颗粒粒径为 $200 \sim 300 \mathrm{~nm}$. 在 $5 \mathrm{C}$ 下循环 100 次后的可逆容量为 $140 \mathrm{mAh} \cdot \mathrm{g}^{-1}$, 表现出了优秀的 循环稳定性.

除了上述以 $\mathrm{Li}_{4} \mathrm{Ti}_{5} \mathrm{O}_{12}$ 为核的研究之外，研究者们还 合成了以 $\mathrm{Li}_{4} \mathrm{Ti}_{5} \mathrm{O}_{12}$ 为壳的核壳结构负极材料, 并对其相 关电化学性能进行了探究 ${ }^{[85 ~ 89]}$.

Lee 等 ${ }^{[85]}$ 混合中间相碳微球 $(\mathrm{MCMB})$ 与 $\mathrm{Li}_{4} \mathrm{Ti}_{5} \mathrm{O}_{12}$, 结合溶胶凝胶法和固相法获得了 $\mathrm{Li}_{4} \mathrm{Ti}_{5} \mathrm{O}_{12}$ 包覆 $\mathrm{MCMB}$ 的核壳结构材料. 结果显示, $\mathrm{Li}_{4} \mathrm{Ti}_{5} \mathrm{O}_{12}$ 以 $80 \sim 120 \mathrm{~nm}$ 的壳均匀包覆在 $\mathrm{MCMB}$ 核周围. 实验证明, 由于 $\mathrm{Li}_{4} \mathrm{Ti}_{5} \mathrm{O}_{12}$ 壳的存在, 在低倍率下该核壳结构的放电比容 量有明显增加, $1 \mathrm{C}$ 下的放电量为 $177 \mathrm{mAh} \cdot \mathrm{g}^{-1}$, 但在 4 $\mathrm{C}$ 下的放电量仅为 $38 \mathrm{mAh} \cdot \mathrm{g}^{-1}$, 倍率性能极差.

为了提高其倍率性能, Shen 等 ${ }^{[86]}$ 制备了以多壁碳纳 米管为核, $\mathrm{Li}_{4} \mathrm{Ti}_{5} \mathrm{O}_{12}$ 晶体为壳的复合负极材料. 其中, $\mathrm{Li}_{4} \mathrm{Ti}_{5} \mathrm{O}_{12}$ 晶体以 $25 \mathrm{~nm}$ 的厚层均匀包覆在碳纳米管周围 (如图 13), 在 $10 \mathrm{C}$ 和 $20 \mathrm{C}$ 下的首次放电量分别为 136.3 和 $123.6 \mathrm{mAh} \cdot \mathrm{g}^{-1}$, 显示出好的倍率性能, 由于碳纳米管 有利于 $\mathrm{Li}^{+}$的快速脱嵌, 该材料有望应用于大倍率工作 

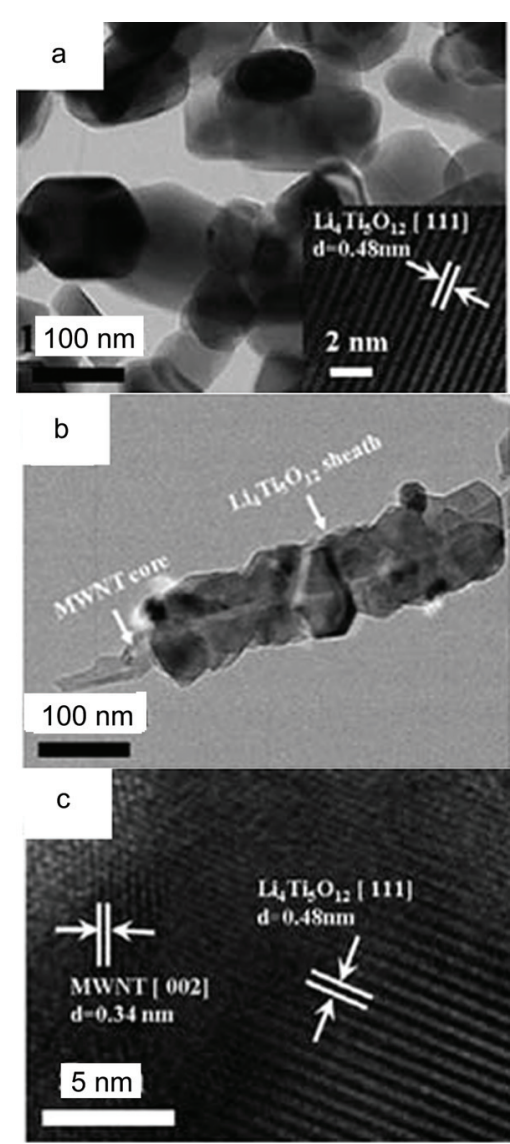

图 13 (a) 无 MWNT 时得到的 $\mathrm{Li}_{4} \mathrm{Ti}_{5} \mathrm{O}_{12}$ 样品 TEM 图, (b, c) MWNT@ $2 \mathrm{Li}_{4} \mathrm{Ti}_{5} \mathrm{O}_{12}$ 的 TEM 和 HRTEM 图 ${ }^{[86]}$. [原文引用]-由英国皇家化 学学会许可转载.

Figure 13 (a) TEM images of the $\mathrm{Li}_{4} \mathrm{Ti}_{5} \mathrm{O}_{12}$ sample synthesized under the control experiment in the absence of MWNT, (b, c) TEM and HRTEM images of MWNT@ $\mathrm{Li}_{4} \mathrm{Ti}_{5} \mathrm{O}_{12}$ coaxial nanocables ${ }^{[86]}$. [Original citation] - Reproduced by permission of The Royal Society of Chemistry.

的锂离子电池以及超级电容器中.

通过不同碳材料与 $\mathrm{Li}_{4} \mathrm{Ti}_{5} \mathrm{O}_{12}$ 复合形成的负极材料 虽然能够大幅提高电导率和倍率性能, 但还是不能满足 高能量密度电源的需求, 而 $\mathrm{SnO}_{2}$ 以高达 $1494 \mathrm{mAh} \cdot \mathrm{g}^{-1}$ 的理论容量而引起人们的巨大兴趣 ${ }^{[87]}$. Xiong 等 ${ }^{[88]}$ 用溶 胶凝胶法制得具有核壳结构的 $\mathrm{SnO}_{2}-\mathrm{Li}_{4} \mathrm{Ti}_{5} \mathrm{O}_{12}$ 纳米复合 物. 通过 TEM 及 $\mathrm{SEM}$ 显示, $\mathrm{Li}_{4} \mathrm{Ti}_{5} \mathrm{O}_{12}$ 以约 $20 \sim 40 \mathrm{~nm}$ 的厚度均匀包覆在 $\mathrm{SnO}_{2}$ 颗粒的表面. 所得产物在 $0.1 \mathrm{C}$ 下的首次放电比容量为 $688.7 \mathrm{mAh} \cdot \mathrm{g}^{-1} .0 .2 \mathrm{C}$ 下的第二 次放电比容量为 $687.6 \mathrm{mAh} \cdot \mathrm{g}^{-1}$, 大幅度提高了 $\mathrm{Li}_{4} \mathrm{Ti}_{5} \mathrm{O}_{12}$ 的放电比容量, 并改善了由于 $\mathrm{SnO}_{2}$ 体积膨胀 带来的循环性差的问题.

以上方法获得的 $\mathrm{SnO}_{2}-\mathrm{Li}_{4} \mathrm{Ti}_{5} \mathrm{O}_{12}$ 核壳结构拥有高的 比容量, 但尚不能满足大倍率功能电池的要求. $\mathrm{Ji}$ 等 ${ }^{[89]}$ 选用水热法两步合成了不同厚度的 $\mathrm{Li}_{4} \mathrm{Ti}_{5} \mathrm{O}_{12}$ 包覆中空 $\mathrm{SnO}_{2}$ 的核壳结构电极材料, $\mathrm{Li}_{4} \mathrm{Ti}_{5} \mathrm{O}_{12}$ 表面 SEI 膜的形成 减小了该材料的不可逆容量, 提高了循环性. 所得材料 中 $\mathrm{SnO}_{2}$ 的厚度均为 $100 \mathrm{~nm}$, 而在 $\mathrm{Li}_{4} \mathrm{Ti}_{5} \mathrm{O}_{12}$ 包覆层厚度 为 $15 \mathrm{~nm}$ 时形成的核壳材料在 $100 \mathrm{~mA} \cdot \mathrm{g}^{-1}$ 的电流密度
下的首次放电量高达 $1030.9 \mathrm{mAh} \cdot \mathrm{g}^{-1}, 1000 \mathrm{~mA} \cdot \mathrm{g}^{-1}$ 下循 环 30 次后的容量稳定在 $439 \mathrm{mAh} \cdot \mathrm{g}^{-1}$, 这种中空结构的 复合材料既具有高的比容量和较好的循环性, 而且在倍 率性方面也有所改善.

总体而言, 核与壳功能的复合与互补, 使得核壳结 构的电极材料具有重要地位, 特别是在提高电极与电池 比容量方面, 相比简单的复合或掺杂更具优势. 未来如 果能够解决其结构不稳定的难题, 进一步提高循环稳定 性, 相信核壳结构必将成为电极材料应用中的佼佼者.

\section{9 总结与展望}

电动汽车等新兴产业的迅猛发展, 对动力电源的安 全性和循环寿命提出了越来越高的要求. 尖晶石型 $\mathrm{Li}_{4} \mathrm{Ti}_{5} \mathrm{O}_{12}$ 具有循环性好、安全可靠、对环境友好, 来源 广泛等优点, 在锂离子动力电池和超级电容器方面具有 广泛的应用价值. 但材料自身也面临着电导率低、倍率 性能差和能量密度低的缺陷. 不同形貌 $\mathrm{Li}_{4} \mathrm{Ti}_{5} \mathrm{O}_{12}$ 的制备 对于解决这些缺陷起到了积极的作用, 各种形貌 $\mathrm{Li}_{4} \mathrm{Ti}_{5} \mathrm{O}_{12}$ 的优点、常用合成方法、已解决和待解决的问 题及适应领域见表 3.

正如表 3 所示, 每种形貌都有相对突出的优点和亟 待解决的问题, 因而未来形貌研究的重点可能在于将两 种或多种形貌的制备交叉结合起来，综合各自的优势， 取长补短, 进一步提高 $\mathrm{Li}_{4} \mathrm{Ti}_{5} \mathrm{O}_{12}$ 的倍率性能和循环性 能. 目前对于多重形貌的组合探索已有相关报道, 如 $\mathrm{Zhu}$ 等 ${ }^{[70]}$ 制备的含碳球形纳微结构就是球形与纳微结 构的组合. 除此之外, 还可以做其它的探索, 例如将纳 微和核壳结构组合, 即纳米核壳粒子组合形成纳微结 构, 或者将多孔与核壳组合, 形成多孔的核壳结构. 更 进一步，甚至可以将纳微、核壳和多孔等结合形成核壳 纳微多孔材料, 这些 $\mathrm{Li}_{4} \mathrm{Ti}_{5} \mathrm{O}_{12}$ 材料多重形貌产生的协同 效应, 可能使电化学综合性能体现出更大的优势.

但 $\mathrm{Li}_{4} \mathrm{Ti}_{5} \mathrm{O}_{12}$ 负极材料能否真正在锂离子动力电池 中大规模的实际应用，除了形貌的控制以外，仍需在以 下三个方面进行更深入的研究: 第一, $\mathrm{Li}_{4} \mathrm{Ti}_{5} \mathrm{O}_{12}$ 能量密 度的进一步提高. 目前的传统方法通过离子掺杂修饰晶 体结构, 借此提高材料的理论容量和降低嵌锂电位. 该 方法虽然相关报道很多，可是令人可喜的成果却极少. 根本原因在于理论容量和嵌锂电位作为材料的固有性 质，由晶体结构决定，仅仅通过修饰晶体结构(晶体结 构保持不变)无法使之发生突变, 因而此方法的研究目 前遇到了巨大的阻碍. 因此, 未来可以通过 $\mathrm{Li}_{4} \mathrm{Ti}_{5} \mathrm{O}_{12}$ 与 其它具有高容量和低电位的负极材料 $\mathrm{M}(\mathrm{M}=\mathrm{Sn}, \mathrm{Si}, \mathrm{Sb}$, $\mathrm{Bi}$ 等)形成特殊结构的复合负极材料. 结合 $\mathrm{Li}_{4} \mathrm{Ti}_{5} \mathrm{O}_{12}$ 和 $\mathrm{M}$ 各自可以互补的优缺点, 以期获得具有优异的循环性 能、倍率性能和安全性能的高能量密度锂离子电池负极 材料. 这些特殊结构包括摇铃结构、核壳结构、纳微结 构等. 第二, 解决或减弱 $\mathrm{Li}_{4} \mathrm{Ti}_{5} \mathrm{O}_{12}$ 电池在存储和充放电 
表 3 不同形貌 $\mathrm{Li}_{4} \mathrm{Ti}_{5} \mathrm{O}_{12}$ 的优点、常用合成方法、已解决和待解决的问题及适应领域

Table 3 The advantages, resolved and unresolved problems, common synthesis methods and application areas of different morphologies $\mathrm{Li}_{4} \mathrm{Ti}_{5} \mathrm{O}_{12}$

\begin{tabular}{|c|c|c|c|c|c|}
\hline 形貌 & 优点 & 常用的合成方法 & 已解决的问题 & 待解决的问题 & 适应领域 \\
\hline 球形颗粒 & $\begin{array}{l}\text { 振实密度高, 体积比容 } \\
\text { 量大 }\end{array}$ & 喷雾干燥法; 水热法 & 倍率性能差, 能量密度低 & 低温性能差 & $\begin{array}{l}\text { 高能量电池例如: 电动 } \\
\text { 自行车等 }\end{array}$ \\
\hline 多孔结构 & $\begin{array}{l}\text { 具有较高的比表面积, } \\
\text { 有利于 } \mathrm{Li}^{+} \text {的快速脱嵌 }\end{array}$ & 溶胶凝胶法; 模板法 & 倍率性能差, 循环性能差 & 孔隙的控制困难 & $\begin{array}{l}\text { 高功率电池和超级电容 } \\
\text { 器例如: 电动工具等 }\end{array}$ \\
\hline 纳米结构 & $\begin{array}{l}\text { 有效缩短 } \mathrm{Li}^{+} \text {的脱嵌路 } \\
\text { 径, 有利于比容量的发 } \\
\text { 挥 }\end{array}$ & $\begin{array}{l}\text { 静电纺丝; 脉冲激光 } \\
\text { 沉积法; 模板法 }\end{array}$ & 电导率低, 倍率性能差 & 加工性能差 & $\begin{array}{l}\text { 高安全性电池例如: 航 } \\
\text { 空电池等 }\end{array}$ \\
\hline 纳微结构 & $\begin{array}{l}\text { 结合了纳米结构和微米 } \\
\text { 结构的优点 }\end{array}$ & 水热法; 溶胶凝胶法 & 电导率低, 倍率性能差 & 合成路线复杂 & $\begin{array}{l}\text { 动力电池例如: 电动汽 } \\
\text { 车等 }\end{array}$ \\
\hline 核壳结构 & $\begin{array}{l}\text { 改善复合电极材料的不 } \\
\text { 均匀性, 有效提高放电 } \\
\text { 容量 }\end{array}$ & 固相法; 溶胶凝胶法 & 电导率低, 能量密度不足 & $\begin{array}{l}\text { 合成路线复杂, } \\
\text { 结构易塌陷 }\end{array}$ & $\begin{array}{l}\text { 长寿命电池例如: 移动 } \\
\text { 电子产品电源 }\end{array}$ \\
\hline
\end{tabular}

过程中严重的产气现象. 研究表明 ${ }^{[90]}, \mathrm{Li}_{4} \mathrm{Ti}_{5} \mathrm{O}_{12}$ 和电解 液溶剂之间的本征界面反应是电池产气的主要原因. 如 何在 $\mathrm{Li}_{4} \mathrm{Ti}_{5} \mathrm{O}_{12}$ 和电解液界面之间建立稳定的隔绝层, 是 未来商品化 $\mathrm{Li}_{4} \mathrm{Ti}_{5} \mathrm{O}_{12}$ 电池急需突破的问题. 目前其隔绝 层为 $\mathrm{Li}_{4} \mathrm{Ti}_{5} \mathrm{O}_{12}$ 的表面包覆层, 包括纳米碳层, 石墨层以 及它们形成的 SEI 膜. 未来的研究重点势必为实现包覆 层的均匀性和稳定性, 以及开拓包覆层的类型(从碳过 渡到其它物质, 从单层过渡到多层). 第三, 探索简单易 行的工业化制备方法. 设计简单经济的工业化合成路线 是 $\mathrm{Li}_{4} \mathrm{Ti}_{5} \mathrm{O}_{12}$ 产业化的必经之路. 因而未来 $\mathrm{Li}_{4} \mathrm{Ti}_{5} \mathrm{O}_{12}$ 的实 验室研究将以此为切入点, 强化工艺方法研究、放大研 究和低成本研究.

综上所述, $\mathrm{Li}_{4} \mathrm{Ti}_{5} \mathrm{O}_{12}$ 作为负极材料的研究热点, 随 着研究的进一步深入, 其优异的电化学性能和安全性能 必将成为未来锂离子电池和电容器市场的一颗璀璨明珠.

\section{作者简介}

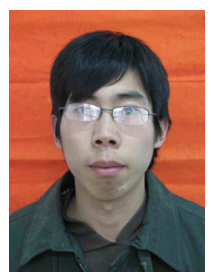

张永龙, 男, 1987 年生, 硕士研究生, 主要从事锂离子电 池钛酸锂负极材料的应用研究工作.

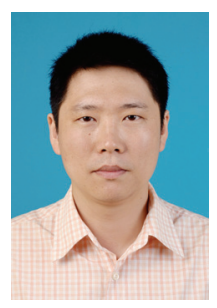

胡学步, 重庆理工大学化学化工学院副教授, 硕士生导 师. 主要从事锂离子电池和超级电容器相关方面的研究.

\section{References}

[1] Yang, L.; Chen, J. Z.; Tang, Y. F.; Fang, S. H. Prog. Chem. 2011, 23, 310. (杨立，陈继章，唐宇峰，房少华，化学进展，2011，23，310.)

[2] Yan, H.; Zhang, H.; Zhang, D.; Zhu, Z.; Qi, L. Acta Phys.-Chim. Sin. 2011，27，2118. (间慧, 张欢, 张鼎, 朱智, 其鲁, 物理化学学报, 2011, 27, 2118.)

[3] Zhang, A.; Zheng, Z. M.; Cheng, F. Y.; Tao, Z. L.; Chen, J. Sci. China Chem. 2011, 54, 936

[4] Zhao, L.; Hu, Y. S.; Li, H.; Wang, Z. X.; Chen, L. Q. Adv. Mater 2011, 23, 1385.

[5] Song, H.; Yun, S. W.; Chun, H. H.; Kim, M. G.; Chung, K. Y.; Kim, H. S.; Cho, B. W.; Kim, Y. T. Energy Environ. Sci. 2012, 5, 9903.

[6] Qiu, C. X.; Yuan, Z. Z.; Liu, L.; Cheng, S. J.; Liu, J. C. J. Inorg. Mater. 2013, 28, 727. (邱彩霞, 袁中直, 刘玲, 程思洁, 刘金成, 无机材料学报, 2013, 28, 727.)

[7] Jiang, S. M.; Zhao, B. T.; Chen, Y. B.; Cai, R.; Shao, Z. P. J. Power Sources 2013, 238, 356.

[8] Gan, L.; Guo, H. J.; Wang, Z. X.; Li, X. H.; Peng, W. J.; Wang, J. X.; Huang, S. L.; Su, M. R. Electrochim. Acta 2013, 104, 117.

[9] Chiu, H.-C.; Brodusch, N.; Gauvin, R.; Guerfi, A.; Zaghib, K.; Demopoulos, G. P. J. Electrochem. Soc. 2013, 160, A3041.

[10] Zhang, C. M.; Zhang, Y. Y.; Wang, J.; Wang, D.; He, D. N.; Xia, Y. Y. J. Power Sources 2013, 236, 118.

[11] Fang, W.; Cheng, X. Q.; Zuo, P. J.; Ma, Y. Y.; Yin, G. Electrochim. Acta 2013, 93, 173.

[12] Wang, W.; Wang, H. L.; Wang, S. B.; Hu, Y. J.; Tian, Q. X.; Jiao, S. Q. J. Power Sources 2013, 228, 244

[13] Lin, J. Y.; Hsu, C. C.; Ho, H. P.; Wu, S. H. Electrochim. Acta 2013, $87,126$.

[14] Bai, Y. J.; Gong, C.; Lun, N.; Qi, Y. X. J. Mater. Chem. A 2013, 1, 89.

[15] Liu, Z. M.; Zhang, N. Q.; Wang, Z. J.; Sun, K. N. J. Power Sources 2012, 205, 479.

[16] Cai, R.; Yu, X.; Liu, X. Q.; Shao, Z. P. J. Power Sources 2010, 195, 8244.

[17] Li, H. S.; Shen, L. F.; Zhang, X. G.; Wang, J.; Nie, P.; Che, Q.; Ding, B. J. Power Sources 2013, 221, 122.

[18] Fang, W.; Zuo, P. J.; Ma, Y. L.; Cheng, X. Q.; Liao, L. X.; Yin, G. P. Electrochim. Acta 2013, 94, 294.

[19] Yang, G. L.; Su, Z.; Fang, H. S.; Yao, Y. C.; Li, Y. M.; Yang, B.; Ma, W. H. Electrochim. Acta 2013, 93, 158.

[20] Zhu, G. N.; Chen, L.; Wang, Y. G.; Wang, C. X.; Che, R. C.; Xia, Y. Y. Adv. Funct. Mater. 2013, 23, 640.

[21] Liu, G. Y.; Wang, H. Y.; Liu, G. Q.; Yang, Z. Z.; Jin, B.; Jiang, Q. C. Electrochim. Acta 2013, 87, 218.

[22] Rai, A. K.; Gim, J.; Kang, S. W.; Mathew, V.; Anh, L. T.; Kang, J.; Song, J.; Paul, B. J.; Kim, J. Mater. Chem. Phys. 2012, 136, 1044.

[23] Gao, J.; Jiang, C. Y.; Wan, C. R. J. Electrochem. Soc. 2010, 157, K39. 
[24] Li, J.; Zhou, Y.; Jin, S. D.; Zheng, Y. Y. Mater. Rev. A 2011, 25, 51. (李军, 周燕, 靳世东, 郑育英, 材料导报 $\mathrm{A}, \mathbf{2 0 1 1}, 25,51$.)

[25] He, Z. J.; Wang, Z. X.; Wu, F. X.; Guo, H. J.; Li, X. H.; Xiong, X. H. J. Alloys Compd. 2012, 540, 39.

[26] Wu, F. X.; Wang, Z. X.; Li, X. H.; Guo, H. J.; Yue, P.; Xiong, X. H.; He, Z. J.; Zhang, Q. Electrochim. Acta 2012, 78, 331.

[27] Kadoma, Y.; Chiba, Y.; Yoshikawa, D.; Mitobe, Y.; Kumagai, N.; Ui, K. Electrochemistry 2012, 80, 759.

[28] Zhao, Y. Y.; Pang, S. P.; Zhang, C. J.; Zhang, Q. H.; Gu, L.; Zhou, X. H.; Li, G. C.; Cui, G. L. J. Solid State Electrochem. 2013, 17, 1479.

[29] Jung, H. G.; Venugopal, N.; Scrosati, B.; Sun, Y. K. J. Power Sources 2013, 221, 266.

[30] Yan, H.; Zhu, Z.; Zhang, D.; Li, W.; Qi, L. J. Power Sources 2012, $219,45$.

[31] Zhang, Z. W.; Cao, L. Y.; Huang, J. F.; Wang, D. Q.; Wu, J. P.; Cai, Y. J. Ceram. Int. 2013, 39, 2695.

[32] Li, C. C.; Li, Q. H.; Chen, L. B.; Wang, T. H. ACS Appl. Mater. Interfaces 2012, 4, 1233.

[33] Wang, J.; Cheng, X. L.; Wang, Z. G.; Yang, H. J. Inorg. Mater. 2010, 25, 235. (王瑾, 成雪莲, 王子港, 杨晖, 无机材料学报, 2010, 25, 235.)

[34] Gao, J.; Jiang, C. Y.; Ying, J. R.; Wan, C. R. J. Power Sources 2006, $155,364$.

[35] Allen, J. L.; Jow, T. R.; Wolfenstine, J. J. Power Sources 2006, 159, 1340 .

[36] Lai, C.; Wu, Z. Z.; Zhu, Y. X.; Wu, Q. D.; Li, L.; Wang, C. J. Power Sources 2013, 226, 71.

[37] Gao, J.; Mu, X.; Li, J. J.; He, X. M.; Jiang, C. Y. J. Inorg. Mater. 2012, 27, 253. (高剑, 穆金金, 李建军, 何向明, 姜长印, 无机材料 学报, 2012, 27, 253.)

[38] Guan, X. F.; Chen, X. M.; Li, G. S. P.; Zang, Y.; Lin, H. F.; Luo, D.; Li, L. P. RSC $A d v$. 2013, 3, 3088.

[39] Lin, Y. S.; Duh, J. G.; Tsai, M. C.; Lee, C. Y. Electrochim. Acta 2012, 83, 47

[40] Feckl, J. M.; Fominykh, K.; Döblinger, M.; Fattakhova-Rohlfing, D.; Bein, T. Angew. Chem. Int. Ed. 2012, 51, 7459.

[41] Kang, E.; Jung, Y. S.; Kim, G. H.; Chun, J.; Wiesner, U.; Dillon, A. C.; Kim, J. K.; Lee, J. Adv. Funct. Mater. 2011, 21, 4349.

[42] Yu, L.; Wu, B. H.; Lou, X. W. Adv. Mater. 2013, 25, 2296.

[43] He, N. D.; Wang, B. S.; Huang, J. J. J. Solid State Electrochem. 2010, 14, 1241.

[44] Yang, K. M.; Hong, Y. J.; Choi, S. H.; Park, B. K.; Kang, Y. C. Int. J. Electrochem. Sci. 2013, 8, 1026.

[45] Han, S. Y.; Kim, I. Y.; Lee, S. H.; Hwang, S. J. Electrochim. Acta 2012, 74, 59.

[46] Choi, H. S.; Im, J. H.; Kim, T.; Park, J. H.; Park, C. R. J. Mater. Chem. 2012, 22, 16986.

[47] Lee, S. C.; Lee, S. M.; Lee, J. W.; Lee, J. B.; Lee, S. M.; Han, S. S.; Lee, H. C.; Kim, H. J. J. Phys. Chem. C 2009, 113, 18420.

[48] Xi, K.; Li, Y. Rare Metal Mater. Eng. 2010, 39, 2051. (郗凯, 李颖, 稀有金属材料与工程, 2010, 39, 2051.)

[49] Li, Y.; Pan, G. L.; Liu, J. W.; Gao, X. P. J. Electrochem. Soc. 2009, $156, \mathrm{~A} 495$.

[50] Wang, L.; Xiao, Q. Z.; Li, Z. H.; Lei, G. T.; Zhang, P.; Wu, L. J. J. Solid State Electrochem. 2012, 16, 3307.

[51] Jo, M. R.; Jung, Y. S.; Kang, Y. M. Nanoscale 2012, 4, 6870.

[52] Shen, L. F.; Uchaker, E.; Zhang, X. G.; Cao, G. Z. Adv. Mater. 2012, 24, 6502 .

[53] Wang, Y. F.; Tang, Y. F.; Qiu, Z.; Yang, L. Electrochemistry 2010, 16, 46. (王怡菲, 唐宇峰, 仇征, 杨立, 电化学, 2010, 16, 46.)

[54] Tang, Y. F.; Yang, L.; Fang, S. H.; Qiu, Z. Electrochim. Acta 2009, $54,6244$.

[55] Li, N.; Mei, T.; Zhu, Y. C.; Wang, L. L.; Liang, J. W.; Zhang, X.; Qian, Y. T.; Tang, K. B. CrystEngComm 2012, 14, 6435.

[56] Han, S. Y.; Kim, I. Y.; Hwang, S. J. J. Phys. Chem. Solids 2012, 73, 1444.

[57] Choi, H. S.; Kim, T. H.; Im, J. H.; Park, C. R. Nanotechnology 2011, 22,405402 .
[58] Deng, J. Q.; Lu, Z. G.; Belharouak, I.; Amine, K.; Chung, C. Y. J. Power Sources 2009, 193, 816.

[59] Kim, K.; Toujigamori, T.; Suzuki, K.; Taminato, S.; Tamura, K.; Mizuki, J. I.; Hirayama, M.; Kanno, R. Electrochemistry 2012, 80, 800.

[60] Mosa, J.; Vélez, J. F.; Lorite, I.; Arconada, N.; Aparicio, M. J. Power Sources 2012, 205, 491.

[61] Wu, X. M.; Liu, J. L.; Chen, S.; Mai, F. R.; Li, C. A. J. Solid State Electrochem. 2012, 16, 3855.

[62] Mani, J.; Katzke, H.; Habouti, S.; Moonoosawmy, K. R.; Dietze, M.; Es-Souni, M. J. Mater. Chem. 2012, 22, 6632.

[63] Woo, S. W.; Dokko, K.; Kanamura, K. Electrochim. Acta 2007, 53, 79.

[64] Sorensen, E. M.; Barry, S. J.; Jung, H. K.; Rondinelli, J. R.; Vaughey, J. T.; Poeppelmeier, K. R. Chem. Mater. 2006, 18, 482.

[65] Choi, D. I.; Lee, H.; Lee, D. J.; Nam, K. W.; Kim, J. S.; Huggins, R. A.; Park, J. K.; Choi, J. W. J. Mater. Chem. A 2013, 1, 5320.

[66] Izumi, A.; Sanada, M.; Furuichi, K.; Teraki, K.; Matsuda, T.; Hiramatsu, K.; Munakata, H.; Kanamura, K. Electrochim. Acta 2012, 79, 218.

[67] Zhang, B.; Liu, Y. S.; Huang, Z. D.; Oh, S.; Yu, Y.; Mai, Y. W.; Kim, J. K. J. Mater. Chem. 2012, 22, 12133.

[68] Fang, W.; Ma, Y. L.; Zuo, P. J.; Cheng, X. Q.; Yin, G. P. Int. J. Electrochem. Sci. 2013, 8, 1949 .

[69] Tang, Y. F.; Yang, L.; Qiu, Z.; Huang, J. H. J. Mater. Chem. 2009, $19,5980$.

[70] Zhu, G. N.; Liu, H. J.; Zhuang, J. H.; Wang, C. X.; Wang, Y. G.; Xia, Y. Y. Energy Environ. Sci. 2011, 4, 4016.

[71] Shen, L. F.; Yuan, C. Z.; Luo, H. J.; Zhang, X. G.; Chen, L.; Li, H. S. J. Mater. Chem. 2011, 21, 14414.

[72] Jung, H. G.; Myung, S. T.; Yoon, C. S.; Son, S. B.; Oh, K. H.; Amine, K.; Scrosati, B.; Sun, Y. K. Energy Environ. Sci. 2011, 4, 1345.

[73] Zhang, Q.; Huang, J. Q.; Qian, W. Z.; Zhang, Y. Y.; Wei, F. Small 2013, 9, 1237.

[74] Bindumadhavan, K.; Srivastava, S. K.; Mahanty, S. Chem. Commun. 2013, 49, 1823.

[75] Shu, J.; Hou, L.; Ma, R.; Shui, M.; Shao, L. Y.; Wang, D. J.; Ren, Y. L.; Zheng, W. D. RSC Adv. 2012, 2, 10306.

[76] Chen, X. M.; Guan, X. F.; Li, L. P.; Li, G. S. J. Power Sources 2012 , $210,297$.

[77] Amine, K.; Belharouak, I.; Chen, Z. H.; Tran, T.; Yumoto, H.; Ota, N.; Myung, S. T.; Sun, Y. K. Adv. Mater. 2010, 22, 3052.

[78] Chen, J. Z.; Yang, L.; Fang, S. H.; Tang, Y. F. Electrochim. Acta 2010, 55, 6596.

[79] Milica, V.; Stojkovic, I.; Mitric, M.; Mentus, S.; Cvjeticanin, N. Mater. Res. Bull. 2013, 48, 218.

[80] Liu, J.; Li, X. F.; Cai, M.; Li, R. Y.; Sun, X. L. Electrochim. Acta 2013, 93, 195.

[81] Shen, L. F.; Li, H. S.; Uchaker, E.; Zhang, X. G.; Cao, G. Z. Nano Lett. 2012, 12, 5673.

[82] Nugroho, A.; Chang, W.; Kim, S. J.; Chung, K. Y.; Kim, J. RSC Adv. 2012, 2, 10805 .

[83] Choi, J.; Lee, S.; Ha, J.; Song, T.; Paik, U. Nanoscale 2013, 5, 3230.

[84] Wang, J.; Zhao, H. L.; Yang, Q.; Wang, C. M.; Lv, P. P.; Xia, Q. J. Power Sources 2013, 222, 196.

[85] Lee, M. L.; Liao, S. C.; Chen, J. M.; Yeh, J. W.; Shih, H. C. J. Chin Chem. Soc. 2012, 59, 1206.

[86] Shen, L. F.; Yuan, C. Z.; Luo, H. J.; Zhang, X. G.; Xu, K.; Zhang, F. J. Mater. Chem. 2011, $21,761$.

[87] Zhou, X. S.; Wan, L. J.; Guo, Y. G. Adv. Mater. 2013, 25, 2152

[88] Xiong, L. Z.; He, Z. Q.; Yin, Z. L.; Chen, Q. Y. Trans. Nonferrous Met. Soc. China 2010, 20, s267.

[89] Ji, G.; Ma, Y.; Ding, B.; Lee, J. Y. Chem. Mater. 2012, 24, 3329.

[90] He, Y. B.; Li, B. H.; Liu, M.; Zhang, C.; Li, J.; Du, H. D.; Zhang, B.; Yang, Q. H.; Kim, J. K.; Kang, F. Y. Sci. Rep. 2012, $2,913$.

(Cheng, B.; Fan, Y.) 